\title{
Inmigración y delincuencia ${ }^{1}$
}

\author{
Ramiro Martínez \\ Associate Professor of Criminology and Criminal Justice, Florida International \\ University \\ Matthew T. Lee \\ Assistant Professor of Sociology, Univesity of Akron
}

\section{RESUMEN}

La relación entre la inmigración y la delincuencia es uno de los temas más controvertidos en la sociedad contemporánea. Estas discusiones no son nuevas, los debates se remontan a más de 100 años. Un punto general sobre el que tanto escritores a favor de la inmigración como los que se manifiestan en contra es que, a medida que entramos en un nuevo milenio, la última ola de inmigraciones probablemente tendrá un impacto más importante sobre la sociedad que cualquier otra cuestión social. En este ensayo revisamos el amplio cuerpo de trabajos teóricos y empíricos sobre la relación entre inmigración y delincuencia en la América del siglo XX. En esta revisión incluimos trabajos más recientes, así como estudios más antiguos a veces olvidados. Presentaremos las tres perspectivas teóricas más importantes que han servido para explicar el vínculo entre inmigración y delincuencia: la estructura de oportunidades, los enfoques culturales, y la desorganización social. También examinaremos estudios empíricos sobre la participación de inmigrantes en la delincuencia. Concluiremos con una evaluación de la opinión pública sobre los inmigrantes, especialmente en lo que concierne a inmigrantes y delincuencia, y presentaremos datos originales sobre la conexión entre opinión pública y la delincuencia de los inmigrantes.

\begin{abstract}
The connection between immigration and crime is one of the most contentious topics in contemporary society. These discussions are not new, as debates on the issue date back more than 100 years. A general point on which both pro- and anti-immigration writers agree is that, as we enter the new millennium, the latest wave of immigration is likely to have a more important impact on society than any other social issue. In this essay, we survey the vast body of theoretical and empirical works on the relationship between immigration and crime in 20th-century America. Throughout, we include new writings as well as older, sometimes neglected works. We discuss three major theoretical perspectives that have guided explanations of the immigration/crime link: opportunity structure, cultural approaches, and social disorganization. We also examine empirical studies of immigrant involvement in crime. We conclude with a review of public opinion about immigrants, especially as it relates to immigrants and crime, and then provide original data on the connection between public opinion and immigrant crime.
\end{abstract}

\section{Palabras clave: inmigración, violencia, homicidios, teoría criminológica}

\section{Introducción}

Existen razones importantes para pensar que los inmigrantes deberían participar en la delincuencia con un mayor grado que las personas nacidas en los Estados Unidos.

\footnotetext{
${ }^{1}$ Este artículo apareció originalmente bajo el título "On Immigration and Crime" en Criminal Justice 2000. The Nature of Crime: Continuity and Change. Volume 1, editado por Julie E. Samuels, Eric Jefferis y Janice Mnsterman (2000) y publicado por el U. S. Department of Justice. Reproducido y traducido con permiso de los autores. Los derechos de autor permanecen con los mismos. Traduccion de Juan José Medina Ariza autorizada por los autores.
} 
Por ejemplo, los inmigrantes encuentran problemas de asimilación y aculturación que la mayoría de los nativos no encuentran y los inmigrantes tienden a encontrar residencia en barrios desorganizados caracterizados por circunstancias estructurales que a menudo están asociadas con la delincuencia, tal y como pobreza, heterogeneidad étnica, y la preponderancia de jóvenes varones. Sin embargo, a pesar de los argumentos presentados por autores y comentaristas que conciben la delincuencia de los inmigrantes como un producto inevitable de la inmigración, los investigadores raramente han producido evidencia sistemática de este problema social que ha vuelto a emerger recientemente.

Aunque existe un conjunto de razones para esperar que los inmigrantes sean especialmente propensos a cometer delitos, la mayoría de los estudios empíricos conducidos durante el siglo pasado han documentado que los inmigrantes típicamente se encuentran infra-representados en las estadísticas criminales.

Existen excepciones parciales a este dato, pero estas excepciones parecen estar más ligadas a las diferencias en las condiciones estructurales entre áreas urbanas donde los inmigrantes encuentran residencia que a las tradiciones culturales de los grupos de inmigrantes. El contexto local es una influencia central que da forma a la participación criminal de los inmigrantes y de los residentes nativos, pero en numerosas ocasiones, cuando los comparamos con los grupos nativos, los inmigrantes parecen estar más capacitados para resistir las condiciones que facilitan la delincuencia que los grupos nativos. En conclusión, esta revisión sugiere que los residentes nativos se beneficiarían de un mejor entendimiento de cómo los grupos de inmigrantes que encuentran condiciones sociales adversas mantienen tasas bajas de delincuencia.

El vínculo entre los inmigrantes y la delincuencia es una de las cuestiones sociales más controvertidas. Las discusiones de esta relación son notablemente controvertidas; tampoco son nuevas, dado que los debates se remontan a más de 100 años. Un punto en el que tanto quiénes están a favor como quiénes están en contra de la inmigración es que a medida que entramos en el nuevo milenio la ola más reciente de inmigrantes probablemente tendrá un impacto más significativo en la sociedad que cualquier otra cuestión social (Suarez-Orozco, 1998; Brimelow, 1996). Si el pasado puede servir de orientación, la relación entre delincuencia e inmigración ocupará un papel central en los esfuerzos para tratar de entender este impacto.

Históricamente, la opinión pública sobre inmigración, y el vínculo de la inmigración a la delincuencia en particular, ha estado más a menudo influenciada por estereotipos que por datos empíricos fiables (Espenshade y Belanger, 1998; Simon, 1985). De forma similar, la política de inmigración a principios del siglo XX se dejó guiar por investigaciones cuestionables y prejuicios más que por unos fundamentos sólidos de conocimiento basados en la literatura científica existente (tal y como es citado en Sellin, 1938). Es por tanto esencial revisar de forma sistemática la literatura sobre inmigración y delincuencia para que los debates públicos y políticos puedan estar mejor informados.

En este ensayo, revisamos el amplio cuerpo de conocimientos teóricos y trabajos empíricos sobre la relación entre delincuencia e inmigración en la América del siglo XX. En este ensayo, incluiremos tanto estudios contemporáneos como otros más antiguos que han sido en ocasiones ignorados. Es importante notar que esta literatura es problemática por, al menos, tres razones (ver Short, 1997; Marshall, 1997): (1) las discusiones sobre un grupo particular de inmigrantes usualmente ocultan las amplias variaciones en las 
condiciones de vida (p.ej., estatus socioeconómico) de las personas de este grupo; (2) el uso de amplias categorías raciales y étnicas a menudo esconde importantes diferencias entre subconjuntos y hace que la realización de comparaciones entre estudios sea difícil (p.ej., los inmigrantes asiáticos pueden ser agrupados conjuntamente en un estudio pero tratados de forma separada en otro estudio como filipinos, chinos, vietnamitas, etc.); y (3) los patrones de participación criminal varían considerablemente entre generaciones de grupos inmigrantes y no hay un criterio aceptado para determinar cuántas generaciones han de pasar para que un grupo de "inmigrantes" sea considerado como un grupo de "nativos".

En la primeara sección, discutiremos las tres perspectivas teóricas más importantes que han guiado las explicaciones del vínculo entre delincuencia e inmigración: estructura de las oportunidades, enfoques culturales y desorganización social (Bankston, 1998). A continuación examinaremos los estudios empíricos sobre la participación de inmigrantes en delincuencia. Hemos organizado este conjunto de estudios en sub-secciones que analizan la relación entre inmigrantes más recientes e inmigrantes más antiguos en la historia de los Estados Unidos. Finalmente, revisamos la opinión pública sobre los inmigrantes, especialmente en lo que se refiere a delincuencia e inmigración, y proporcionamos datos originales sobre la relación entre opinión pública y la delincuencia de los inmigrantes.

\section{Perspectivas teóricas.}

Se han propuesto un número aparentemente infinito de variedades de explicaciones para dotar de sentido a los datos voluminosos y a menudo contradictorios producidos por los estudios que han examinado la relación entre delincuencia e inmigración. Algunos autores a principios del siglo XX en América alegaban que los grupos de inmigrantes eran biológicamente deficientes comparados con los sujetos que no eran inmigrantes y que la delincuencia no era sino uno de los muchos productos deleznables que se pueden esperar como resultado de dejar a inmigrantes "inferiores" entrar en el país. Por ejemplo, un autor temía que la inmigración conduciría a "destruir las cualidades inherentes raciales y familiares -físicas, mentales y espirituales- de la gente en el país receptor de inmigrantes" (Laughlin, 1938, p. 5). Una buena parte de este trabajo de orientación biológica estaba asociado con el desacreditado movimiento eugénico, y aunque fracasó a la hora de facilitar evidencia empírica para respaldar dichos argumentos, estas ideas influyeron la legislación sobre inmigración en los Estados Unidos durante la década de los años 20 (Sellin, 1938; Hagan y Palloni, 1998).

Las teorías que son populares en la actualidad tienden a subrayar variables sociopsicológicas (p.ej., estrés resultante de las presiones de aculturación) o, más a menudo, variables sociológicas (p.ej., desorganización comunitaria). Existe un considerable grado de desacuerdo entre diferentes escuelas de pensamiento sobre la importancia de diferentes factores, pero la mayoría del trabajo teórico se puede clasificar en una de las perspectivas más importantes mencionadas en la próxima sección. Estas explicaciones normalmente emplean varios elementos teóricos, y es ciertamente una invención analítica pensar que los factores "culturales" pueden ser separados de sus contextos "estructurales". 


\subsection{Estructura de oportunidades vitales}

Las teorías de la estructura de la oportunidad destacan las estructuras sociales y materiales que dan forma a los valores y actividades de los grupos en la sociedad americana (Bankston, 1998). Dado que no todos lo grupos sociales tienen el mismo acceso a las oportunidades legítimas para la obtención de riqueza y estatus social, algunos sujetos "innovaran" para tomar ventaja de las oportunidades ilegítimas a su alcance. Este tipo de explicación fue popularizada por Merton (1938) y presta atención a los mecanismos por medio de los cuales los grupos desaventajados (los cuales a menudo incluyen a inmigrantes) pueden ser denegados los medios legítimos (p.ej., trabajos) para alcanzar los objetivos culturalmente sancionados (p.ej., un estilo de vida de clase media). Cloward y Ohlin (1960) añadieron la noción de que algunos grupos, particularmente aquellos que viven en áreas urbanas con un alto nivel de delincuencia, tienen más oportunidades ilegítimas que otros.

Numerosos autores han reconocido desde hace tiempo la tendencia que tienen los nuevos inmigrantes de encontrar acomodo en barrios que se caracterizan por su pobreza, viviendas deterioradas, malas escuelas y altas tasas de delincuencia (Thomas y Znaniecki, 1920; Taylor, 1931; Shaw y McKay, [1942] 1969; Hagan y Palloni, 1998). Segregados en este tipo de barrios, los inmigrantes pueden encontrar en la delincuencia un mecanismo para superar las barreras para tener acceso a oportunidades económicas mientras que en la delincuencia organizada pueden encontrar un mecanismo para penetrar el mundo de la política (Whyte, 1943). Otros autores han sugerido que grupos de inmigrantes sin un pasado criminal pueden verse "contaminados" por las oportunidades criminales que abundan en sus barrios (Lambert, 1970, p. 284; comparar Sampson y Lauritsen 1997 cuando presentan la hipótesis de la proximidad). De conformidad con esta perspectiva, la criminalidad de los inmigrantes es más que nada una función de los factores estructurales pre-existentes tal y como la pobreza (Yeager, 1997); una preponderancia de varones jóvenes solteros (Taft, 1936; Gurr, 1989); o la disponibilidad de alcohol (Alaniz, Cartmill y Parker, 1998) más que una función de las características biológicas o las tradiciones culturales del grupo de inmigrantes.

Las pandillas juveniles y bandas contemporáneas pueden ser conceptualizadas como un mecanismo alternativo para asegurar riqueza y estatus en áreas urbanas en las que los inmigrantes están concentrados y en las que la pérdida de trabajos de cuello azul ha socavado la base principal de ascenso social empleada por generaciones anteriores de inmigrantes (Gans, 1992). Los hábitos de la vida en las fabricas asociado con la revolución industrial socializaron las olas anteriores de inmigrantes (p.ej., italianos, irlandeses) y facilitaron su estabilidad económica y su asimilación en la cultura americana, suprimiendo así su participación criminal (Lane, 1997). Pero la desaparición en la actualidad de trabajos en la industria, ligados a la transición de un modelo económico orientado a la manufacturación hacia uno orientado a la prestación de servicios, ha tenido consecuencias drásticas en las oportunidades legítimas (e ilegítimas) en las ciudades americanas (cf. Wilson, 1987; Anderson, 1990). Aunque la desindustrialización afecta tanto a inmigrantes como a no inmigrantes, los recién llegados (que se encuentran cultural y económicamente en los márgenes de la sociedad americana) pueden encontrar los beneficios potenciales de la "economía informal" particularmente atractivos (Bankston, 1998; Vigil y Long, 1990). Dado que la posibilidad de ser 
miembro de una banda no está abierta a todo el mundo y está, de hecho, normalmente basada en la identidad étnica entre otras cosas (Sánchez-Jankowski, 1991), la disponibilidad de oportunidades ilegítimas en las bandas es una variable estructural que influye de forma diferente a la delincuencia de los inmigrantes entre unidades sociales tal y como ciudades y barriadas.

\subsection{Enfoques culturales.}

Además de estos factores estructurales, los autores han destacado cómo factores culturales también juegan un papel en la participación criminal, y en particular en la delincuencia de los inmigrantes. La tesis de la "cultura de la pobreza" -que destaca como la gente con escasos ingresos se adapta a sus condiciones estructurales en formas que perpetúan su condición de pobreza- es un ejemplo de explicación cultural (Lewis, 1965). Así, participar en la delincuencia es una forma de adquirir estatus social que aleja a los niños de las tareas escolares, lo que reduce sus probabilidades de mejorar su situación económica en el futuro. Una variante de esta explicación de la delincuencia, la tesis de la "subcultura de la violencia", sugiere que la violencia puede llegar a convertirse en un mecanismo "normal" y esperado para resolver disputas en áreas económicas marginadas (Wolfgang y Ferracuti, 1967).

Dado que los inmigrantes y las minorías étnicas son más propensas que los nativos blancos a residir en este tipo de áreas, estas teorías culturales podrían ser particularmente útiles. Sin embargo, como Sampson y Lauritse (1997) destacan, la teoría de la subcultura de la violencia no puede explicar las amplias variaciones en tasas de delincuencia violenta que existen entre barrios poblados por minorías étnicas y que presentan diversas condiciones estructurales, de ahí que concluyan que las condiciones estructurales son en última instancia más importantes que las tradiciones culturales. Bankston (1998) también nota que el hecho de que existan pandillas en grupos de inmigrantes marginados diversos implica que éstas son el producto de condiciones estructurales similares que estos sufren más que un resultado de las tradiciones culturales de un grupo específico en particular. Finalmente, sería un error atribuir las tasas comparativamente mayores de forma de delincuencia menor, tal y como el juego y las apuestas ilegales entre los portorriqueños que llegaban a Nueva York en la década de los 50, a sus tradiciones culturales específicas, dado que otros grupos marginados nativos, como los afroamericanos, también exhibían tasas elevadas de estas formas delictivas. Como Handlin (1959, p 101) señala, ninguno de estos grupos consideraba las apuestas y el juego como una forma delictiva. De hecho, los juegos de apuestas vienen a representar el ideal americano de progreso económico.

No obstante, algunos autores sugieren que ciertos tipos de delitos son más prevalentes entre específicos grupos de inmigrantes por razón de las tradiciones culturales importadas de su país de origen. Tanto Sutherland (1947) como Sellin (1938) argumentaban que los grupos de inmigrantes tienen "predisposiciones criminales" hacia ciertos delitos. Por ejemplo, en la década de los 20 , los italianos tenían tasas altas de condenas por homicidios, pero tasas bajas de detenciones por borrachera (Sutherland y Cressey, 1960). Un estudio de Hawai en el mismo período revelaba que los inmigrantes chinos traían consigo tradiciones de cierto tipo de juegos y apuestas ilegales (Lind, 1930b). 
Una versión prominente de la teoría cultural que se encuentra particularmente bien posicionada para explicar la relación entre delincuencia e inmigración puede ser encontrada en los escritos de Sellin (1938) sobre "conflicto cultural". Sellin (p. 21) reconocía que el derecho penal refleja los valores de los "grupos de interés dominante" en la sociedad, y que los valores de otros grupos sociales, particularmente los de los inmigrantes, son muy diferentes. En casos en los que los códigos culturales de los grupos dominantes y los grupos subordinados entran en conflicto, los agentes de la ley etiquetan como desviada la conducta de los miembros de las clases subordinadas. No obstante, el criminal puede estar actuando de conformidad a normas subculturalmente aceptadas y sentir que no existe un "conflicto mental" cuando viola la ley. Sellin (p. 68) proporciona un ejemplo clásico:

"Hace unos cuantos años un padre siciliano en Nueva Jersey mató al seductor de 16 años de su hija, expresando sorpresa a su detención dado que se había limitado a defender el honor familiar de conformidad a la forma tradicional. En este caso, no existía un conflicto mental en el sentido sociológico"

Así, Sellin (p. 69) distingue entre conflicto "interno" (mental) que puede estar ligado a sentimientos de culpabilidad o vergüenza de los conflictos "externos" (a escala de los códigos culturales) que no presentan estos sentimientos. A medida que la sociedad se hace más compleja por medio de los procesos de diferenciación (la inmigración siendo solamente uno de estos procesos), el potencial para los conflictos entre "códigos culturales" operativos también aumenta.

Cuatro años más tarde, Sutherland (1934, p. 51-52) ofrecía una explicación similar, señalando que "el conflicto de culturas es, por tanto, el principio fundamental en la explicación de la delincuencia [y]... mientras mayores sean los patrones de conflicto cultural, más difícil de predecir será la conducta de los individuos". Esta tesis se puede aplicar a todos los grupos sociales, pero claramente presenta una razón clave para entender porque los inmigrantes participan en la delincuencia, quizás sugiriendo que los inmigrantes deberían tener mayores tasas de delincuencia que la población nativa, en tanto que otros factores causales se mantengan constantes.

Otra vertiente de la literatura que se inserta en la tradición cultural se ha centrado en el análisis de los procesos por medio de los cuales los inmigrantes se adaptan a las tradiciones del país receptor (Padilla, 1980). Se ha mantenido durante mucho tiempo que la "aculturación" a un nuevo ambiente implica el "ajuste a normas heterogéneas de conducta" y esto, en consecuencia, puede conducir a mayores tasas de delincuencia (Sellin, 1938, p. 85). Las pandillas de inmigrantes, por ejemplo, generalmente presentan vínculos tanto a las tradiciones culturales americanas como a las de la cultura de origen de los inmigrantes; los vietnamitas adultos en los Estados Unidos se refieren a los jóvenes delincuentes vietnamitas como "americanizados" (Bankston, 1998). Las pandillas de inmigrantes también se forman como reacción a las tensiones étnicas en diversos barrios; las pandillas ofrecen protección física de otras pandillas con una identidad étnica diferente y sirven para mantener la identidad étnica frente a las presiones de la asimilación cultural (Chin, 1990; Du Phuoc Long, 1996).

Otros trabajos empíricos y teóricos sobre aculturación y delincuencia han encontrado que la delincuencia entre los jóvenes coreanos americanos varía en función del modo de aculturación: separación, asimilación, y marginalización. De forma muy interesante, los jóvenes asimilados eran más propensos a cometer actos delictivos que 
aquellos que estaban separados o marginados (Lee, 1998). De forma similar, Stepick (1998) documentó que los niños haitianos en el sur de Florida se ajustaban a los extremos sentimientos anti-haitianos haciéndose pasar por afroamericanos. De forma creciente, estos niños están empezando a recibir sanciones penales como consecuencia de su alienación de la sociedad de inmigrantes haitianos y la sociedad americana.

\subsection{Desorganización social}

La perspectiva de la desorganización social, aunque no niega la importancia de factores culturales o estructurales, añade a estas otras perspectivas una preocupación por la ruptura de las instituciones sociales de la comunidad que resultan de cambios sociales. Bursik (1988, p. 521) de forma concisa describe las áreas desorganizadas como aquellas que poseen "la inhabilidad para desarrollar y alcanzar los valores comunes de los residentes o para resolver los problemas de los mismos". En barrios organizados, las instituciones locales de la comunidad trabajan juntas para alcanzar los objetivos de la comunidad, proteger sus valores, y en general para controlar la conducta de los miembros de la comunidad en formas que son consistentes con estos objetivos y valores. Bankston (1998) destaca que la inmigración puede minar las instituciones establecidas por medio de un proceso de cambio demográfico, mientras que al mismo tiempo hace más difícil alcanzar acuerdos sobre lo que constituyen valores comunes. La implicación es que cuando los controles sociales de la comunidad se debilitan la delincuencia florece.

Uno de las presentaciones más influyentes y antiguas de esta perspectiva fue la esbozada por Thomas y Znaniecki en los cinco volúmenes del trabajo publicado entre 1918 y 1920 titulado El campesino polaco en Europa y América. Thomas y Znaniecki escribieron sobre los numerosos cambios sociales que afectaron a los campesinos polacos durante este período, incluyendo las influencias desorganizadoras inherentes en desplazarse desde las áreas rurales, simples y homogéneas de Polonia a las áreas urbanas, complejas y heterogenias de los Estados Unidos. Estos autores definen la desorganización social como "la disminución de la influencia de las reglas sociales existentes sobre la conducta de los miembros individuales de un grupo" (Thomas y Znaniecki, 1920, p. 20). La efectividad de las reglas sociales (p.ej, leyes) derivan del vínculo de los individuos con las mismas (p.ej., actitudes favorables a la ley). En una sociedad organizada, hay una congruencia entre las reglas del grupo y las actitudes individuales. La desorganización implica una separación entre las reglas y las actitudes, de tal forma que los individuos no se sienten obligados por las leyes y se consideran libres para desobedecerlas (p.ej., participar en la delincuencia). Visto desde esta perspectiva, la desorganización era un término neutral que sugería la posibilidad de cambio social, tanto positivo como negativo, y la liberación individual de los estándares opresivos de la comunidad, aunque generalmente es un concepto que se ha aplicado a los estudios de la delincuencia. Una contribución de esta literatura es el reconocimiento de que la delincuencia no solamente es una función de fuerzas económicas (p.ej., pobreza) o culturales (subcultura de la violencia), sino que se encuentra íntimamente ligada a los procesos fundamentales de cambio social.

Thomas y Znaniecki (1920, p. 82-83) describen dos tipos generales de desorganización que afectan las comunidades (y otras organizaciones tal y como la familia). La primera, especialmente relevante para las comunidades de inmigrantes, causa 
un descenso en la solidaridad cuando la generación más joven adopta los valores de la nueva comunidad en lugar de los valores tradicionales del "viejo mundo" sustentados por la generación de los padres (ver también Schneider sobre "anomia cultural"). Un ejemplo es la influencia de las escuelas americanas en los niños inmigrantes -aprender un nuevo lenguaje y valores genera deseos en los niños de adquirir experiencias que la generación más vieja no puede proporcionar, reduciendo de forma simultanea la habilidad de la comunidad y de los padres para controlar su conducta (ver también Young, 1936). El segundo tipo de desorganización ocurre entre los miembros de la generación más vieja a medida que sus valores son sometidos a interpretación diferencial con el paso del tiempo o a medida que las reglas no son aplicadas, conduciendo a la "falta de armonía social".

Aunque no estaban particularmente interesados en la delincuencia, Thomas y Znaniecki ([1920] 1984) aplicaron la idea de la desorganización a la delincuencia de los inmigrantes polacos. Los homicidios entre los polacos, por ejemplo, tenían una etiología muy diferente en Polonia en comparación con los que ocurrían en Estados Unidos. Los homicidios entre polacos en Polonia estaban confinados al pequeño grupo comunal de cada uno, los homicidios de desconocidos eran raros. El motivo (p.ej., venganza) en estos casos era sentido de forma más intensa y generalmente era precedido de largos periodos de conflicto, así como de un sentimiento de violación de lo que se percibían como valores profundos. En contraste, los homicidios en América cometidos por inmigrantes polacos tendían a envolver una víctima que era un desconocido o que no era muy cercana al agresor y tenía una probabilidad menor de estar ligados a la seriedad de una violación de un estándar tradicional de la comunidad. En las áreas desorganizadas de América en la que los inmigrantes polacos viven, las ataduras sociales que existían en Polonia han desaparecido y los controles comunitarios se han debilitado. Liberados de estos controles sociales tradicionales y sometidos a fuerzas sociales que influyen sus vidas en formas que no pueden controlar o comprender, algunos inmigrantes polacos exhiben un nivel "general de nerviosismo" y una "expectativa, vagamente definida, de hostilidad" (Thomas y Znaniecki, 1984, p. 286) que eran virtualmente desconocidas en el país de origen. En tales circunstancias, el homicida puede ser provocado por ofensas triviales en apariencia porque el inmigrante siente la necesidad de adoptar acciones individuales contra afrentas dado que:

"el homicida no se siente respaldado en sus tratos con el resto del mundo por un grupo social fuerte y no es consciente de ser miembro de un grupo social organizado. Su familia es demasiado débil y se encuentra demasiado dispersa como para darle un refugio social seguro... donde pueda ignorar las provocaciones externas y se sienta importante y seguro (Thomas y Znaniecki, 1984, p. 286).

Así, la debilitada comunidad polaca en América era incapaz de resolver disputas y organizar la conducta tal y como se hacía en el país de origen y esto tenían implicaciones para un conjunto de problemas sociales, incluyendo la delincuencia.

A pesar del voluminoso trabajo de Thomas y Znaniecki, los investigadores de forma más común asocian la perspectiva de la desorganización social a los escritos de Shaw y McKay (1931, [1942]. 1969; ver también Ross, 1937; Kobrin, 1959) sobre la distribución ecológica de la delincuencia. Shaw y McKay utilizaron el concepto de desorganización social con un gran efecto por medio del uso de datos cuantitativos de los barrios de Chicago para especificar el papel de la desorganización comunitaria en la producción de la delincuencia, una vez que se controlaban otras condiciones (p.ej, 
pobreza residencial, raza). Su resultado más importante era que "dentro del mismo tipo de área social, los nacidos en otros países y los residentes oriundos, los inmigrantes recién llegados y los inmigrantes que llevan más tiempo en el país producen tasas de delincuencia muy similares" (Shaw y McKay, 1969, p. 158). O, en las palabras de uno de sus críticos, "la natividad y la nacionalidad no se encuentran relacionadas a la delincuencia juvenil" (Jonassen, 1949, p. 613). Los datos de Chicago sugerían a Shaw y McKay (aunque no a Jonassen) que ciertas áreas tenían tasas delictivas más altas de forma consistente, con independencia de que grupo de inmigrantes residía en las misma, y que los grupos de inmigrantes que se mudaban desde estas áreas a barrios mejores, experimentaban un descenso en la delincuencia.

Inspirados por Thomas y Znaniecki, la explicación teórica sugerida por estos patrones es que los barrios caracterizados por factores "desorganizadores" tal y como cambios rápidos de población y un alto grado de heterogeneidad étnica tienen una capacidad menor que otros barrios para controlar la conducta de sus habitantes. De acuerdo con este punto de vista, los inmigrantes solamente presentaran tasas elevadas de delincuencia cuando residan en barrios desorganizados, y su participación en actividades delictivas no se debe a factores biológicos o a tradiciones culturales criminales. Así, Lind 1930a, 1930b) destaca la importancia de distinguir "ghettos" pobres, pero homogéneos, de los "slums" pobres, pero desorganizados. Desde este punto de vista, la delincuencia florece en los "slums", pero no en los "ghettos", incluso cuando ambos pueden ser definidos por su marginación económica y otras condiciones sociales negativas, dado que los residentes de los "ghettos" ejercen un grado de control sobre sus vecinos que no se da en los barrios desorganizados (Lind, 1930a). Sin embargo, estudios recientes en los ghettos afroamericanos han documentado que áreas homogéneas desde el punto de vista étnico no se encuentran mejor organizadas para ejercer el control social (Anderson, 1990) y también sufren la concentración de múltiples problemas sociales (Sampson y Wilson, 1995). No hay estudios contemporáneos sobre inmigración que se inserten en esta tradición.

El trabajo teórico reciente de Sampson y Lauritsen (1997) ha intentado demostrar como fuerzas estructurales macro-sociales y que operan al nivel de la comunidad local pueden ser combinadas para desarrollar el marco clásico de la teoría de la desorganización social. Aunque este trabajo ha sido desarrollado en el contexto de tratar de explicar las diferencias entre las tasas delictivas entre blancos y negros y para explicar las amplias diferencias en las tasas de delitos de afro-americanos que viven en áreas comunitarias estructuralmente diferentes, la teoría puede también servir para desarrollar nuestro conocimiento de la relación entre inmigración y delincuencia. Sampson y Lauritsen sugieren que poderosos factores estructurales (p.ej., segregación, discriminación en el mercado inmobiliario, las transformaciones de la estructura de la economía) coinciden con factores que operan al nivel de la comunidad local (p.ej., cambios rápidos de la población, concentración de la pobreza, ruptura familiar) para impedir la organización social de las zonas marginales de las ciudades (p. 340; ver también Sampson y Wilson, 1995). Una comprensión más profunda de la forma en que estas variables interaccionan entre sí podría mejorar las teorías existentes por medio de la consideración de los "masivos cambios sociales" (Sampson y Lauritsen, 1997, p. 340) experimentado por los residentes, mayoritariamente de color, de las zonas marginales de las ciudades americanas en la década de los 70 y la de los 80 . En el momento en que la 
ola de inmigración que comienza a partir de 1965 trajo a un número de inmigrantes y los puso en las mismas condiciones estructurales, podríamos esperar una alta tasa de delincuencia de inmigrantes durante este periodo histórico. Esta cuestión es el objeto de la próxima sección sobre los estudios empíricos de la relación entre delincuencia e inmigración.

\section{Estudios empíricos}

Ha habido dos grandes olas de inmigración a los Estados Unidos durante el siglo XX. La primera consistió sobre todo de europeos y canadienses y transcurrió hasta mediados de los años 20 cuando el congreso aprobó leyes que frenaron el largo flujo de inmigrantes. La segunda ola, comúnmente conocida como "la nueva inmigración", comienza después de 1965, alcanzó su momento cumbre a principios de los 90 y estaba dominada por caribeños, asiáticos y latinos (Suarez-Orozco, 1998; Hagan y Palloni, 1998). México es en la actualidad la mayor fuente de inmigrantes, legales e ilegales (Baker et al., 1998). En la siguiente sección, consideramos algunos de los mayores estudios sobre inmigración y delincuencia conducidos durante las dos olas.

\subsection{Estudios más antiguos}

En un reciente estudio histórico, Roger Lane (1997, p. 298) concluía que el "homicidio en el mundo moderno ha sido sobre todo un delito irracional e impulsivo, cometido por hombres jóvenes, especialmente los pobres y los desesperados motivados por la frustración y el enfado". Lo mismo podría decirse de otros delitos. Dado que la inmigración trae un numero desproporcionado de jóvenes varones a los países receptores, podríamos esperar que los inmigrantes exhiban tasas de delincuencia mayores que las de la población nativa. En algunos casos, esto es precisamente lo que ha ocurrido (Gurr, 1989; Monkkonen, 1989). Al margen de esta cuestión demográfica, cada una de las perspectivas teóricas presentadas previamente ofrecen razones convincentes por las que los inmigrantes deberían presentar tasas más elevadas de delincuencia. Los inmigrantes normalmente encuentran acomodo en comunidades desorganizadas con altos niveles de pobreza y delincuencia y encuentran problemas de ajuste que los grupos nativos no experimentan. También, muchos inmigrantes se desplazan desde áreas rurales a áreas urbanas y esto también conlleva una influencia desorganizadora de las estructuras comunitarias y familiares (Young, 1936). De hecho, el crecimiento urbano y la inmigración normalmente ocurren de forma simultanea y los aumentos en la delincuencia son a menudo más una función del proceso de urbanización que de cualquier otro factor (Handlin, 1959). Sin embargo, los datos resultantes de un siglo de investigación sobre la relación entre delincuencia e inmigración es que los inmigrantes muestran una variación muy amplia, a escala temporal y espacial, en su participación criminal y que, de forma contraria a la opinión popular, casi siempre exhiben una tasa de delincuencia menor que la de los grupos de nativos (Hagan y Palloni, 1998; Tonry, 1997; Ferracuti, 1968; Sellin, 1938).

Los primeros estudios sobre la delincuencia de la primera ola de inmigrantes, que acabó en 1924, estaban basados en evidencia que, en el mejor de los casos, ofrecía resultados mixtos (Tonry, 1997, p. 21). Estos estudios sugerían que los recién llegados 
eran menos propensos a cometer delitos que los nativos. Un informe especial preparado por la Comisión Industrial en 1901 encontró que "los blancos extranjeros eran menos criminales que los blancos nativos", mientras que la Comisión de Inmigración de 1911 concluía que "la inmigración no ha aumentado el volumen de la delincuencia" y que la presencia de los inmigrantes puede incluso haber suprimido la actividad criminal (Tonry, 1997, p. 21). Una revisión de otros estudios sobre inmigración y delincuencia de esta época descubrió que, en contra de los estereotipos, la mayoría de los investigadores no encontraron que los inmigrantes de la primera ola de la inmigración fueran más propensos a cometer delitos (McCord, 1995), aunque los resultados variaban de ciudad a ciudad (p.ej., los inmigrantes en Boston, pero no en Chicago, se encontraban sobrerepresentados en las muestras de criminales). Estos estudios generalmente encontraban que los hijos de los inmigrantes tenían tasas más altas de delincuencia que sus padres, pero no tasas más altas que la de los hijos de los nativos. Esto sugiere que la aculturación a la vida americana de la segunda generación de inmigrantes, y no las presumidas "tradiciones criminales" de los grupos de inmigrantes, estaban relacionadas a las tasas de delincuencia de los inmigrantes (Hagan y Palloni, 1998; Sellin, 1938; Sutherland, 1934). La aculturación aparentemente debilitaba el impacto de los controles sociales tradicionales en las comunidades de inmigrantes.

Aun así, los estudios de la primera ola de inmigrantes respaldan la conclusión de que los inmigrantes comente menos delitos que los nativos (Abbott, 1915; Lind, 1930b; Taft, 1936; Ferracuti, 1968). Un informe famoso publicado en 1931 por la Comisión Nacional de la Obediencia y Aplicación de la Ley, popularmente conocido como el Informe Wickersham, notaba que los inmigrantes presentaban en general tasas de delincuencia menores que los no inmigrantes, aunque algunos grupos aparecían de forma desproporcional en tipos específicos de delincuencia. Los mejicanos en un estudio, por ejemplo, presentaban mayores tasas de detenciones policiales por delitos violentos que los blancos nativos (aunque menores que las de los negros nativos; ver Bowler, 1931, p. 119). Sin embargo, como Taylor (1931), y más tarde Sellin (1938, p. 76), señalaron, estas tasas no eran muy fiables porque no había estimaciones fiables de la población de mejicanos dada la naturaleza migratoria de dicho grupo, una situación que se hizo peor como consecuencia de que las figuras del censo de 1930 no se encontraban aun disponibles (Taylor, 1931).

Las tasas de inmigrantes también eran poco fiables por otras razones. Otro autor del informe de 1931 señalaba formas en que los prejuicios contra los mejicanos por parte del personal de la justicia penal servía para inflar sus tasas de detenciones (Warnhuis, 1931). Por ejemplo, la policía en una comunidad con una presencia mejicana grande expresaba la creencia de que la mayoría de los delitos eran cometidos por mejicanos, mientras que un examen de las detenciones revelaba que solamente 4 mejicanos del total de 252 personas detenidas eran acusados de algún delito en el plazo de un mes; 3 de los mismos eran acusados de violaciones del orden público y ninguno recibió condena. En términos de estadísticas oficiales, los prejuicios policiales tenían consecuencias prácticas cuando se cometían delitos de seriedad: la policía en ocasiones detenía a "todos los mejicanos que pudieran encontrar" (p. 253), inflando de forma artificial las tasas de delincuencia de los mejicanos.

A pesar de las limitaciones de los datos sobre la delincuencia de los mejicanos, Taylor (1931) fue capaz de extraer varias conclusiones. En primer lugar, el número de 
delitos cometidos por los mejicanos era la mitad de lo que se podía esperar considerando el número de mejicanos en la población y las tasas de delincuencia de los mejicanos eran similares a aquellas de otros grupos. En segundo lugar, los patrones de detenciones por la comisión de actos delictivos variaban considerablemente entre ciudades y estaban influenciadas por un amplio conjunto de factores sociales, incluyendo la pobreza, así como la distribución de edad y sexo de la población de inmigrantes. Taylor (p. 235) también descubrió que la participación criminal de los mejicanos mostraba "una interesante diversidad dentro de una misma localidad", sugiriendo la necesidad de examinar los factores estructurales que afectan de forma diferente en áreas sociales significativas tal y como los barrios, más que a la escala de divisiones políticas más amplias como las ciudades o los Estados. Resumiendo, no se podía extraer una conclusión sencilla sobre las tasas de delitos cometidos por los mejicanos sin tener en cuenta el contexto comunitario.

Este último punto fue investigado por Lind (1930a, 1930b) en su trabajo sobre inmigración y delincuencia en la ciudad étnicamente diversa de Honolulu en Hawai. Siguiendo a los proponentes de la escuela sociológica de Chicago como Robert Park y Louis Wirth, Lind $\left(1930^{\mathrm{a}}\right.$, p. 206-207) subrayaba la distinción entre "slums" -barrios pobres, inestables y étnicamente diversos- y los "ghettos", que se encontraban también sometidos a marginación económica, pero que estaban caracterizados por grupos de residentes estables, organizados y racialmente más homogéneos (ver también la distinción que Whyte, 1943 hace entre "rooming houses" y "settlement districts"). Lind encontró que la heterogeneidad y la inestabilidad de los barrios, los grupos en los "slums" tenían múltiples códigos morales y eran menos efectivos a la hora de organizar las familias y las instituciones comunitarias para controlar la conducta de los residentes. Así, la delincuencia era rara en los barrios japoneses que eran pobres, pero estables, mientras que era elevada en los barrios de los nativos hawaianos que residían en áreas menos pobres, pero más desorganizadas (Lind, 1930b). Además, Lind (1930a p. 209) documentó que las tasas de delincuencia cometida por los japoneses también variaban en función del grado de segregación del barrio y de concentración de la población. Estos datos ofrecen respaldo empírico al argumento de que la delincuencia de los inmigrantes es una función de un proceso genérico (p.ej., la desorganización) asociado con la vida en las ciudades más que el producto de tradiciones culturales o predisposiciones de los inmigrantes (ver también Shaw y Mc Kay, 1969).

Otras investigaciones encontraron que comparados a los grupos nativos, algunos grupos inmigrantes eran capaces de resistir en mayor medida los efectos desorganizadores de los barrios marginales que los grupos de nativos. Un estudio demostraba que aunque los inmigrantes japoneses en Seattle vivían en áreas económicamente pobre, con alta delincuencia y desorganización social, su "sólida organización comunitaria y familiar" fue capaz de mantener las tasas de delincuencia de sus hijos a un nivel bajo (Hayner, 1933, p. 319). Esto es consistente con los resultados ofrecidos por Taft $(1936$, p. 736) que mostraban que los inmigrantes generalmente presentaban tasas más bajas de delincuencia que los no inmigrantes y que las variaciones podían ser explicadas por la combinación de "condiciones adversas" que se encuentran en las tasas de delincuencia elevada y los efectos marginalizadores de los "valores culturales que diferentes grupos nacionales traen". Von Hentig (1945, p. 793; en contraste Glueck y Glueck,1930) también ofrece resultados similares: Los descendientes de los grupos de 
nativos presentaban mayores niveles de delincuencia severa que los descendientes de familias de inmigrantes o familias en las que uno de los padres era un inmigrante, aunque existían enormes diferencias entre los Estados. De nuevo, la combinación de condiciones ecológicas y culturales parecen importantes para explicar la participación de los inmigrantes en la delincuencia o su ausencia.

\subsection{Estudios contemporáneos}

La investigación científica y el interés público sobre la inmigración y la delincuencia prácticamente desapareció en los Estados Unidos en el segundo tercio del siglo XX (Hagan y Palloni, 1998). Esto no es sorprendente dado que la inmigración también era baja durante este periodo de tiempo y grandes segmentos de la primera ola de inmigrantes (p.ej., italianos, inmigrantes) habían sido asimilados en la sociedad americana (Lane, 1997). Pero a la ola de inmigración que comienza en 1965 (fundamentalmente de latinos, asiáticos y caribeños) ha generado un nuevo interés en el tema, en parte porque la llegada de estos inmigrantes coincidió con aumentos en las tasas de delincuencia en los Estados Unidos desde finales de los 60 y durante los 70.

Algunos autores han sugerido que la delincuencia de los inmigrantes estaba comenzando a convertirse en un problema cada vez más serio durante los 90 , tal y como está evidenciándose en el aumento de procesamientos penales de delincuentes que no tienen la ciudadanía americana en los tribunales de distrito de los Estados Unidos entre 1984 y 1994 ( de 3.462 a 10.352 casos respectivamente; ver Marshall, 1997). Sin embargo, este dato no toma en consideración el tremendo aumento en inmigración sobre este período de tiempo y es fundamentalmente el resultado de un aumento en el procesamiento penal de delitos relacionados con drogas así como de delitos de inmigración que solamente pueden tener como sujeto activo a los inmigrantes. Tal y como discutimos en la siguiente sección, la opinión pública continua asociando a los inmigrantes con la delincuencia, por lo que es importante revisar los estudios más recientes que han investigado esta relación.

La Comisión de la Reforma de la Inmigración de 1994 comparó la delincuencia en las ciudades a lo largo de la frontera con México con ciudades no fronterizas para valorar el impacto de los inmigrantes mejicanos en las tasas de delincuencia. La Comisión concluyó que las tasas de delincuencia en las ciudades fronterizas tal y como El Paso, Texas, generalmente presentaban tasas de delincuencia más bajas (en algunos casos incluso mucho más bajas) que las ciudades no fronterizas. Además de la comparación de las tasas de delincuencia entre ciudades, análisis de regresión revelaron que "la delincuencia como promedio es más baja en las áreas fronterizas que en otras ciudades estadounidenses cuando las características de la población urbana son mantenidas constantes" (1994, p. 20). Un estudio de seguimiento condujo una prueba estadística más directa del efecto de la inmigración en los niveles de la delincuencia y encontró "la ausencia de evidencia convincente o consistente de que al nivel de las áreas metropolitanas los niveles de inmigración causan la delincuencia" (Hagan y Palloni, 1998, p. 380).

Una buena parte del trabajo reciente sobre inmigración y delincuencia se ha centrado en el estudio de pandillas (Bankston, 1998; Marshall 1997). Esto no debería sorprendernos, dado que los nuevos inmigrantes a menudo encuentran acomodo en áreas 
urbanas caracterizadas por niveles elevados de actividad de pandillas, y muchas pandillas de inmigrantes se forman como mecanismo de protección frente a las amenazas existentes en dichos entornos (Chin, 1990). Aunque ha habido numerosos estudios de específicas pandillas de inmigrantes (cf. Du Phuoc Lang, 1996), no ha habido estudios que de forma sistemática comparen el nivel de participación de inmigrantes en pandillas en contraste con el nivel de participación de los nativos o que sugiera razones para defender la noción de que la inmigración aumenta el nivel de actividad de las pandillas (Bankston, 1998).

Después de 1965, los estudios sobre inmigración y delincuencia, más allá de los estudios sobre pandillas, han sido raros (Martínez y Lee, 1999). Los estudios que han sido conducidos han tendido a confirmar los resultados de los estudios sobre la primera ola de inmigrantes: los inmigrantes no cometen más delitos que los residentes oriundos y a menudo presentan tasas menores de delincuencia. Por ejemplo, la investigación sobre homicidios en San Antonio encontró que la tasa de homicidios entre varones mejicanos se ubica entre la tasa de los blancos nativos y los afroamericanos y que los homicidios permanecían concentrados desde 1940 a 1980 en las áreas pobres de la ciudad, con independencia de si los residentes eran negros o mejicanos (Bradshaw et al., 1998). Otro estudio encontró que la inmigración no se encontraba relacionada a la violencia juvenil en California, mientras que la facilidad de acceso al alcohol era una influencia muy importante en los niveles de delincuencia severa entre los jóvenes varones en tres ciudades con una población elevada de latinos (Alaniz, Cartmill y Parker, 1998). Finalmente, un estudio de portorriqueños recién llegados encontró que aquellos que vivían en la ciudad de Nueva York tenían tasas elevadas de homicidios, mientras que los portorriqueños que vivían en otras partes de Estados Unidos tenían tasas comparables a los de la población oriunda blanca (Rosenwaike y Hempstead, 1990).

Un número de estudios ha examinado los homicidios entre varios grupos étnicos importantes en Miami. Aunque los refugiados de Mariel a menudo eran presentados en los medios de comunicación social como voraces asesinos, la evidencia empírica demostraba que rara vez se encontraban representados de forma desproporcionada en las tasas de víctimas o perpetradores de homicidios $\mathrm{y}$, de hecho, pasado un tiempo, eran mucho menos propensos a cometer delitos que otros cubanos establecidos en Miami (Martinez, 1997a). Además, a pesar de un flujo constante de inmigrantes latinos durante los años 80, la tasa de homicidios de Miami continuaron descendiendo de forma constante (Martínez, 1997b). Finalmente, Martínez y Lee (1998) encontraron que los haitianos y los latinos residentes en Miami se encontraban infra-representados en las tasas de homicidio en relación con el tamaño de estos grupos en la población general, mientras que los afroamericanos se encontraban sobre-representados, y en algunos casos la tasa de homicidio entre estos dos grupos de inmigrantes era menor que la de los blancos que no eran latinos (anglos).

De forma consistente con los estudios más antiguos, la participación criminal de los grupos de inmigrantes varía de ciudad a ciudad de forma muy considerable. Un buen ejemplo de esta variación es ofrecida por un estudio sobre los homicidios de latinos entre los mejicanos de El Paso y los cubanos de Miami (Lee, Martínez y Rodríguez, 2000). A pesar de la similitud de las características estructurales de las dos ciudades (p.ej., desempleo, pobreza), los homicidios latinos en Miami eran tres veces mayores que los de El Paso. Además de características específicas de las ciudades tal y como la mayor vejes 
de la población de Miami, o sus mayores niveles de desigualdad de ingresos económicos (ver Martínez, 1996, para una discusión sobre deprivación absoluta versus deprivación relativa entre latinos), y la mayor facilidad de acceso a pistolas, otras condiciones locales influían la relativamente alta tasa de homicidios de cubanos. Por ejemplo, los cubanos encontraron acomodo en una de las áreas más violentas del país (el sur de Florida) a diferencia de los latinos en El Paso y este contexto regional pudo influir la participación de cada grupo en los homicidios. Wilbanks (1984; ver también Epstein y Greene, 1993) demostró que los homicidios en Miami refleja las tasas de los homicidios en el sur de Florida de forma general y que este área experimentó un dramático aumento en homicidios antes de la llegada de miles de refugiados cubanos en el episodio de Mariel en 1980. Así, los latinos de Miami vivían en una localidad que experimentaba unos niveles mayores de violencia que los latinos en El Paso.

Tan importante como las diferencias reveladas por la experiencia de estos dos grupos de latinos descritos en el párrafo anterior, otros estudios también han examinado la existencia de diferencias internas dentro de un mismo grupo étnico de inmigrantes (ver Hawkins, 1999 para una estrategia similar). Martinez y Lee (2000) investigaron los homicidios de afro-caribeños en Miami y encontraron que los inmigrantes cubanos de Mariel, los haitianos y los jamaicanos presentaban niveles menores de homicidio que los nativos. Comparando los datos de principios de los 80, cuando estos grupos comenzaron a llegar a Miami en grandes números, a los de finales de los 90, los autores notaban un patrón consistente y sólido de descenso de la violencia, especialmente para los jamaicanos y los marielitos, mientras que los haitianos han mantenida de forma continua una tasa generalmente baja de homicidios. A medida que estos grupos de inmigrantes crecieron en tamaño y descendía la proporción de jóvenes varones, las tasas de homicidios descendían con rapidez. Este resultado sugiere que, de forma contraria a las proposiciones clave de la teoría de la desorganización social la inmigración rápida en lugar de crear comunidades desorganizadas, puede contribuir a estabilizar los barrios de inmigrantes por medio de la creación de nuevas instituciones sociales y económicas (ver también Portes y Stepick, 1993).

Las conclusiones generales de los estudios recientes sobre inmigración y delincuencia reflejan como un eco los temas encontrados en los estudios más antiguos. En el pequeño numero de estudios que ofrecen evidencia empírica, los inmigrantes generalmente cometen menos delitos que otros grupos que ocupan una posición social similar, a pesar de que una buena parte de las teorías criminológicas más importantes ofrecen buenas razones por las que este no debería ser el caso (p.ej., residencia en barrios desorganizados, dificultades de aculturación, conflictos entre códigos culturales). Además, las experiencias de inmigración varían enormemente con las condiciones locales, como es ilustrado por los estudios de cubanos en Miami y mejicanos en El Paso y es probable que estas condiciones locales influyan la participación criminal de los inmigrantes en mayor medida que las tradiciones culturales de estos grupos. A continuación revisaremos la persistente opinión pública sobre inmigrantes y delincuencia.

\section{Opinión pública sobre inmigración y delincuencia}

Rita Simon (1985, 1987, 1993) señala que, con independencia del momento histórico, la opinión pública casi siempre se ha mostrado en sentido negativo sobre la 
cuestión de si se debería permitir a más inmigrantes el entrar en los Estados Unidos (ver también Espenshade y Belanger, 1998). Además, los inmigrantes más recientes son percibidos casi siempre de forma desfavorable, aunque la opinión pública sobre específicos grupos de inmigrantes usualmente mejora con el paso del tiempo (Informe Roper, 1995). De acuerdo con Simon (1987, p. 47), las comunidades étnicas más antiguas son vistas de forma más positiva que los que grupos más recientes, incluso si en un momento inicial los miembros de las comunidades más antiguas también eran percibidos de forma negativa.

Por ejemplo, los chinos y los japoneses hoy en día son percibidos de forma más favorable que en la década de los 20, aunque hubo una época en la que estuvieron sometidos a legislaciones discriminatorias y a actitudes públicas cargadas de prejuicios (Abbott, 1931). De forma similar, la opinión pública se mostraba en contra de los irlandeses, italianos y polacos en la década de los 20, pero estos grupos étnicos blancos son generalmente mejor vistos hoy en día, al menos en las encuestas más recientes. Una encuesta de 1985 mostraba que 82 eminentes sociólogos pensaban que el grupo actual de inmigrantes (sobre todo latinos), tal y como la mayoría de los americanos durante el siglo pasado, es de alguna forma diferente de los grupos más antiguos de inmigrantes: son percibidos como menos propensos a asimilarse y especialmente peligrosos a los valores e instituciones culturales de los americanos (Simon, 1993)

Además de esta cuestión temporal, las opiniones sobre los inmigrantes no se encuentran distribuidas de una forma uniforme entre los grupos sociales -en general las personas con una educación avanzada, trabajos de prestigio e ingresos superiores tienen opiniones más favorables de todos los inmigrantes con independencia de su país de origen (Simon, 1987), aunque algunas encuestas han señalado que comparados con otros grupos, los afroamericanos y los latinos tienen una mayor estima de los inmigrantes (Espenshade y Belanger, 1998). Sin embargo, cambios pequeños en la forma en que se redactan las preguntas en estas encuestas se reflejan en resultados radicalmente diferentes en las actitudes medidas de los entrevistados. Por ejemplo, los inmigrantes que han vivido en los Estados Unidos durante los últimos cinco años son percibidos de forma más favorable que los recién llegados. También es indicativo que en las encuestas que se incluyen las preguntas sobre inmigración dentro del contexto más amplio de temas sociales, la inmigración ocupa un lugar más bajo que otros temas tal y como la delincuencia o empleos (Espenshade y Belanger, 1998).

Para ubicar los sentimientos actuales en contra de la inmigración en su debido contexto, es informativo examinar las tendencias sobre la opinión del vínculo entre inmigración y delincuencia a lo largo del siglo XX. Como Ferracuti (1968, p. 190; ver también Short, 1997; Abbott, 1931) señala, durante la primera mitad del siglo XX', "la opinión popular a menudo expresaba el punto de vista de que los inmigrantes eran responsables de una fracción importante de la tasa delictiva", a pesar de que existía considerable evidencia empírica que mostraba que esto no era así. Afirmaciones como la siguiente, de un jefe de policía de la ciudad de Nueva York, eran típicas: "entre el 85\% y el 100\% de nuestros criminales posiblemente tienen un origen exótico" (Simon, 1985, p. 70-71). Este jefe de policía consideraba a los italianos como maleantes particularmente peligrosos (Simonm 1985, p. 71) y pensaba que los franceses y los belgas estaban detrás del trafico organizado de esclavos blancos. 
La idea de los inmigrantes como delincuentes no es un producto del siglo XX; una serie de artículos en el New York Times publicados en 1880 también se preocupaban con la criminalidad de los italianos, una "raza particularmente orientada a los clanes", y el prototípico "joven problemático irlandés [que era] un producto tan indeseable como se puede encontrar en cualquier sociedad" (Simon, 1985, p. 186). Nótese también que en 1892 el Partido Democrático respaldaba leyes orientadas a mantener a los Estados Unidos como un país que no se convirtiera en "el basurero de Europa y China al que se manda a criminales conocidos" (Simon, 1985, p. 18). Estos puntos de vista se habían venido reflejando desde antaño en los escritos académicos. Por ejemplo, un articulo de William Jeffrey en el volumen de 1893 de la Revista de Economía Política también culpaba a los inmigrantes de los aumentos en las tasas de delincuencia (Simon, 1985).

Esta imagen ocupaba un lugar prominente en los periódicos publicados durante la primera ola de inmigración. En una editorial de 1915 en el North American Review se demandaba una restricción de la inmigración alegando "el carácter criminal y la falta de utilidad económica" de los inmigrantes del sur de Europa (Simon, 1985, p. 71). Artículos publicados en otras revistas populares también expresaban la pobre opinión que se tenía de los inmigrantes. Un número de 1923 del Saturday Evening Post veía a los inmigrantes del sudeste de Europa (italianos y griegos) como "a la gente más estúpida y aburrida en Europa", mientras que otro del mismo año citaba a Harry Laughlin, asociado al pensamiento eugenésico, diciendo que "si América no cierra sus puertas a los extranjeros mongolizados del sur y este de Europa, sus ciudadanos acabaran tan mongolizados y enanizados como estos" (Simon, 1985, p. 85). La naturaleza criminal del inmigrante es un tema común en estas narrativas, con la mayoría de los autores señalando que los inmigrantes estaban llenando las cárceles y los manicomios. Durante la década de los 20, los italianos, los judíos, los polacos, los rusos y los griegos eran normalmente presentados como criminales.

Los sentimientos contemporáneos en contra de la inmigración a menudo son promovidos por grupos de interés organizados que acusan a los países del Tercer Mundo de exportar sus números excesivos de ciudadanos a los Estados Unidos (Simon, 1993, p. 69). Y, como en el pasado (Sellin, 1938), la normativa más reciente -tal y como la Proposición 187 en California y la Ley de Reforma de la Inmigración del Congreso de los Estados Unidos de 1996- no se ha apoyado en la investigación académica y ha sido justificada sobre la base de que había que frenar la ola de "inmigrantes delincuentes", que se habían convertido en una presencia cada vez mayor en las instituciones del sistema de justicia penal (Comisión sobre la Reforma de la Inmigración de los Estados Unidos, 1994; Scalia, 1996). Esta imagen pública ha tenido profundad consecuencias para los inmigrantes más recientes que han tenido que confrontar estos negativos estereotipos duraderos, que sufren discriminación y que son vistos por la opinión pública, tal y como se refleja en sondeos de opinión, como una carga para la sociedad (Simon, 1987; Informe Roper, 1995).

Una de las consecuencia de los prejuicios contra los inmigrantes se puede apreciar en el aumento de violencia racista contra los americanos de origen asiático que han tenido lugar en algunas comunidades durante los 80 (Zinsmeister, 1987). Los ciudadanos en áreas en los que los inmigrantes asiáticos encontraban acomodo creían que estos inmigrantes habían salido de "pueblos en la jungla", comían perros y competían de forma desleal en el mercado laboral porque trabajan "día y noche" (Zinsmeister, 1987, p. 8). 
Gore Vidal reflejaba esta última preocupación en un artículo publicado en 1986 en la revista Nation, aludiendo que al menos que los Estados Unidos y Canadá cooperasen entre sí y limitaran el número de inmigrantes asiáticos, los americanos iban a terminar convirtiéndose en un "mero entretenimiento" para los asiáticos (p. 350). Estas ideas, cuando unidas a la creencia tradicional de que los inmigrantes son una población altamente criminal, facilita el resentimiento contra los inmigrantes que puede incrementar la probabilidad de la violencia racista.

\section{Opinión pública y homicidios de inmigrantes en tres ciudades}

Como punto de partida, en la siguiente sección nos centraremos en las tasas de victimación homicida, no en las tasas de comisión de homicidios. Aunque la mayor parte de nuestra discusión se ha centrado en la motivación de los delincuentes, el vínculo entre inmigración y delincuencia debería ser también evidente en los análisis de las tasas de victimación por homicidio dada conocida proximidad de agresor y víctima en la mayoría de los casos. Las estadísticas policiales (Uniform Crime Reports, UCR) publicadas por el FBI en 1995 señalaban que en el 75\% de los casos de homicidios resueltos por medio de una detención, la víctima y el agresor tenían algún tipo de relación previa (matrimonio, relación familiar, amante, amigo, vecino) o contactos previos (conocidos, compañeros de trabajo). Así, en la mayoría de los casos, los homicidios son cometidos por conocidos con similares características sociodemográficas. Es más, la gran mayoría de los homicidios son intrarraciales (blancos matan a blancos, los afroamericanos matan a afroamericanos) lo que es en parte un correlato de los patrones de segregación social y residencial que han caracterizado a la sociedad americana. La mayoría de las personas tienden a vivir en áreas en las que los otros residentes tienen atributos similares, incluyendo la raza y la etnicidad.

Además, la mayoría de los estudios históricos y contemporáneos sugieren que la mayoría de los homicidios fueron "precipitados" por la víctima en el sentido de que normalmente los homicidios son altercados que acaban con la muerte de uno de los contendientes (Wolfgang, 1958; Martinez y Lee, 1998). La proximidad de esta relación se puede ilustrar de forma más clara en un reciente estudio que examinaba los niveles de homicidios con víctimas blancas y de color en de distintas ciudades. Ousey (1999, p. 410) indicaba que los efectos de las condiciones estructurales en las tasas de homicidio basadas en el perfil de la víctima o de los agresores son sustancialmente similares y ofrecen las mismas conclusiones. Esto no debería sorprendernos dada la proximidad espacial entre víctimas y agresores, la mayoría de los cuales reside en el mismo barrio y comparten similares características económicas (Anderson, 1990). De hecho, ambas tasas son el producto de comunidades debilitadas por un conjunto de problemas sociales que limitan la habilidad de las instituciones locales para mantener el orden y proporcionar oportunidades a aquellas personas que más las necesitan y son típicamente más activos criminalmente en general y en relación con la violencia en particular.

Finalmente, problemas con los datos también recomiendan el emplear datos de las víctimas. Los homicidios son eventos relativamente raros en comparación con otros delitos violentos (robos con violencia, lesiones). Desagregar estos eventos raros en función de las características étnicas de los participantes, disminuye el número de casos disponibles para los análisis, estimulando a los investigadores a emplear todos los 
homicidios sobre los que existen datos relativos a las víctimas. Además, no existen amplias bases de datos que estén disponibles que ofrezcan de forma fiable información sobre toda la conducta delictiva de los latinos. Los críticos de este análisis pueden sugerir que nuestros análisis se limitan a las ciudades que examinamos. Admitimos que existe la posibilidad de que nuestros resultados difieran de los de otros autores, pero de nuevo, la mayoría de nuestros casos implicaba a miembros del mismo grupo y en todas las instancias, los perfiles de los datos sobre víctimas y sobre agresores se parecían los unos a los otros. Por tanto, las tasas de victimación ofrecen un indicador aproximado valioso, aunque no completamente satisfactorio, de las tasas de perpetración de cada grupo étnico.

A pesar de los argumentos realizados por autores y comentadores de opinión que indican que la relación entre inmigración y tasas elevadas de delincuencia es inevitable, existen pocas investigaciones científicas que han producido recientemente evidencia sistemática de este problema que ha vuelto a emerger en nuestros días (Beck, 1996; Hagan y Palloni, 1998; Sampson y Lauritsen, 1997). Como Hagan y Palloni destacan, dado que la inmigración supone un aumento del total de la población -especialmente de la población joven de varones sin ataduras familiares-, es probable que se registre un aumento en el nivel absoluto de delincuencia. La cuestión fundamental es en qué medida los inmigrantes contribuyen de forma desproporcional a la delincuencia más allá de lo que se podría esperar de la contribución de la población oriunda con similares características demográficas. Como la Figura 1 sugiere, la reciente ola de inmigrantes (fundamentalmente de latinos) no parece haber tenido un efecto en las tasas de homicidios de latinos ${ }^{\mathrm{ii}}$.

Aunque la teoría y la opinión popular sugieren que los inmigrantes deberían participar de forma desproporcional en la delincuencia, las tendencias presentadas en la Figura 1 muestran que las tasas de homicidios de latinos han permanecido claramente estables a pesar del aumento masivo de inmigrantes latinos durante los 90. Datos similares que no encuentran una relación sistemática entre inmigración y tasas de delincuencia han sido también presentadas para la ola de inmigrantes que llegaron en la primera mitad del siglo XX (Hagan y Palloni, 1998, p. 369). En la sección final de este ensayo, exploraremos la relación entre opinión pública, contexto local y delincuencia de inmigrante presentando datos de victimación que no han sido publicados previamente en castellano.

En esta sección presentamos los resultados empíricos para el periodo más reciente de un estudio sobre homicidio de inmigrantes en tres ciudades El Paso, Miami y San Diego. Existe poca evidencia que señale que la violencia entre latinos en estas ciudades, en las que casi un tercio de la población procede de otro país, se encuentra influenciada de forma sistemática y persistente por los altos niveles de inmigración. A pesar de este dato, la opinión pública ha seguido siendo muy negativa sobre la cuestión de si la llegada de específicos grupos ha sido "una buena cosa para el país", lo que sugiere que estos grupos de inmigrantes sufren prejuicios y, posiblemente, dificultades para ajustarse a la sociedad americana (Informe Roper, 1995). Como la Figura 2 demuestra, solamente un pequeño porcentaje de los americanos (en ningún caso más del 27\%) tiene opiniones favorables sobre los inmigrantes enumerados. Aunque las actitudes positivas hacia los mejicanos y los vietnamitas doblan las actitudes hacia cubanos y haitianos, estas actitudes positivas son todavía minoritarias. En comparación, los inmigrantes europeos (ingleses, irlandeses, y otros grupos de la primera ola de inmigrantes) son generalmente percibido 
de forma mucho más favorable que los nuevos inmigrantes. Por ejemplo, el $45 \%$ de los entrevistados en 1995 puntuaba a los irlandeses de forma favorable (Informe Roper, 1995).

Antes de entrar a examinar las tasas de homicidio específicas de cada grupo, en la medida que estas pueden estar influenciadas por actitudes públicas desfavorables, presentamos las tasas totales de homicidio para las tres ciudades en este estudio. Hemos comentado a lo largo de este ensayo la importancia de las condiciones locales en la génesis de la delincuencia de los inmigrantes, por lo que es importante ubicar la participación de grupos de inmigrantes en los homicidios dentro de su contexto local. Dado que los datos sobre victimas son más completos que los datos sobre agresores, y dado que aproximadamente entre el $20 \%$ y el $25 \%$ de los casos de homicidio no son resueltos por medio de una detención y se desconoce al agresor, las tasas de victimación por homicidio son empleadas como indicadores aproximados de los homicidios. Las tasas de perpetración de homicidio de cada grupo étnico, al menos en estas ciudades, en la medida que se puede discernir, siguen las mismas tendencias que los datos sobre victimación por homicidio, lo que nos permite tener una confianza razonable en que nuestro argumento se puede aplicar a todos los casos de homicidio.

Como la Figura 3 señala, las tasas de homicidio por 100.000 habitantes en Miami son mucho más elevadas que en San Diego e en El Paso, por lo que deberíamos esperar que este resultado impacte en el homicidio de inmigrantes. Por lo tanto, en las figuras que siguen, las tasas de homicidio de los grupos de inmigrantes serán comparadas con las tasas locales y nacionales relevantes. En muchas de las figuras, las tasas de los inmigrantes son similares a las tasas locales y nacionales ${ }^{\text {iii }}$.

Probablemente existen algunas instancias únicas para los latinos y otros en los que cambios en actitudes públicas y tasas de victimación cambian a medida que pasa el tiempo. Pongamos, por ejemplo, el caso del episodio de Mariel en el que casi 125.000 personas escaparon de Cuba, la mayoría de las cuales acabaron el sur de Florida (ver Portes y Stepick, 1993). Los medios de comunicación social populares vinculan estos refugiados a las tasas de delincuencia en Miami, ya de por si excesivamente elevadas, etiquetándolos como escoria, o basura, liberada de las prisiones cubanas y que generó una enorme cantidad de publicidad negativa sobre este grupo étnico en general (ver Aguirre, Saenz y James, 1997). Como vemos en la Figura 4, la tasa de victimación por homicidio de los marielitos era superior a las tasas en Miami entre 1980 y 1986. Sin embargo, los marielitos nunca presentaron niveles de victimación superiores a los de los afroamericanos y aparentemente aterrizaron en Miami durante un periodo general de crisis urbana (ver Martínez, 1997). Esto no es para sugerir que los marielitos no estaban sobrerepresentados en la delincuencia. De hecho, ellos contribuyeron, como otros, a las elevadas tasas de delincuencia en Miami, pero al mismo tiempo, no fueron en general un grupo de inmigrantes predispuestos a la criminalidad tal y como de difundió en los medios de comunicación social. La contribución de los marielitos a la tasa local de homicidio se concentró en unos pocos años y tras estos disminuyó de forma notable, ubicándose a un nivel inferior al de la contribución de otros grupos de latinos y residentes de Miami e incluso por debajo de la media nacional para ciudades del tamaño de Miami.

Las actitudes negativas hacia los cubanos persistieron durante un periodo más largo que la etapa inicial de publicidad negativa. Empleando el trabajo de Portes y Stepick (1993) como punto de partida, notamos que el porcentaje de la población 
nacional que mostraba su acuerdo con la afirmación de que "Los inmigrantes cubanos son una buena cosa para los Estados Unidos" se encontraba por debajo del 10\% y solamente ascendía al $17 \%$ en 1995 , de acuerdo con los datos más recientes de los Informer Roper (ver figura 2). Esto ocurría incluso a pesar del considerable descenso en la violencia de los marielitos en Miami, donde la mayoría de los refugiados encontraron acomodo.

Las mimas actitudes negativas se dan en las ciudades de la frontera con México. La opinión pública hacia los mejicanos nunca se hacía eco de las tasas persistentemente bajas de victimación por homicidios de los latinos (mejicanos) en las dos ciudades fronterizas más grandes (El Paso y San Diego).

La tasa de homicidios en estas dos ciudades nunca se aproximo al de otras ciudades de tamaño similar (ver Figuras 5 y 6). La figura 2 muestra como las actitudes nacionales hacia los mejicanos permanecieron constantes, y a partir de ahí empeoraron, a pesar de las bajas tasas de homicidio entre los procedentes de Méjico.

La conexión entre tasas bajas de victimación y la percepción pública es quizás más clara en el caso de los haitianos de Miami, como se muestra en la Figura 7. Miami no es el único punto de destino para los afrocaribeños, pero es el hogar de la segunda comunidad más grande de haitianos en los Estados Unidos. Sin embargo, de nuevo, las actitudes públicas hacia los haitianos rara vez han sido favorables (ver Figura 2) y, de hecho, están empeorando considerablemente a pesar de que los haitianos presentan tasas de homicidio menor que las de cualquier grupo étnico en Miami e incluso más bajas que la de la tasa promedio en las ciudades de tamaño similar a Miami durante los 90.

Finalmente, examinamos las tasas de homicidio entre los inmigrantes asiáticos en San Diego (fundamentalmente vietnamitas) en la Figura 8 y comparamos estas tasas con las actitudes públicas hacia los vietnamitas. A primera vista, el nivel de homicidios entre los asiáticos parece bajar y luego subir; sin embargo, la tasa nunca se eleva por encima de un dígito (7,5 a 8,0 por 100.000 asiáticos en San Diego). De hecho, la tasa de asiáticos se encuentra por debajo de la tasa total de San Diego y bastante por debajo de la tasa de las ciudades con más de un millón de habitantes. A pesar de ello, esto no se ha traducido en actitudes positivas hacia los vietnamitas de forma apreciable durante el periodo de este estudio (ver Figura 2). Como otros grupos de inmigrantes, los asiáticos siguen siendo vistos de forma desfavorable a pesar de su relativamente baja participación en la delincuencia, al menos cuando se mide por medio de tasas de homicidios.

Aparentemente, las actitudes nacionales hacia diversos grupos étnicos no se encuentran en línea con las tasas de delincuencia (si asumimos que debería existir una actitud positiva hacia grupos con una tasa baja de delincuencia), pero que se hallan en su lugar influidas por estereotipos raciales o étnicos, más que por lo que sugieren los resultados empíricos.

\section{Conclusiones}

Podemos extraer un número de conclusiones generales de esta revisión sobre inmigración y delincuencia en los Estados Unidos durante el siglo XX. En primer lugar, hay buenas razones teóricas para pensar que los inmigrantes deberían exhibir tasas de delincuencia más elevadas que las de los residentes oriundos. Por ejemplo, los inmigrantes encuentran problemas de aculturación que los nativos no confrontan y los 
inmigrantes tienden a encontrar residencia en barrios desorganizados caracterizados por condiciones estructurales negativas tal y como la pobreza, altos grados de heterogeneidad étnica, preponderancia de jóvenes varones, y posiblemente mas oportunidades criminales en la forma de pandillas. También, los códigos culturales de los inmigrantes pueden entrar en conflicto con los códigos legales construidos por los grupos oriundos. A pesar de éstas y otras razones que podrían sugerir tasas elevadas de delincuencia para los inmigrantes, la mayoría de los estudios empíricos conducidos durante el siglo XX han documentado que los inmigrantes normalmente se encuentran infra-representados en las estadísticas criminales. Existen variaciones en relación con este resultado general, pero estas parecen ser el producto de diferencias en las condiciones estructurales de las áreas en las que los inmigrantes encuentran acomodo mas que el producto de las tradiciones culturales de los grupos de inmigrantes. El contexto local parece ser la influencia más importante que explica la participación en la delincuencia tanto de los inmigrantes como de los residentes nativos, aunque en muchos casos, los inmigrantes parecen ser más capaces de resistir las influencias criminógenas de estos ambientes que los grupos de nativos.

Existen varias razones por las que las tasas de delincuencia de los inmigrantes son más bajas de lo que cabría esperar. De forma contraria a lo que indica la tradición de investigación sociológica sobre violencia urbana que se remonta al trabajo pionero de Thomas y Znaniecki (1920), es posible sugerir que la inmigración contemporánea no crea comunidades desorganizadas sino que sirve para estabilizar los barrios por medio de la creación de nuevas instituciones sociales y económicas. Los inmigrantes residen en barrios pobres pero atenúan los efectos de estas condiciones locales por medio de la mayor prevalencia de familias extendidas e intactas y por medio del contacto regular con el mundo del trabajo. Moore y Pinderhughes (1993) notan que los inmigrantes latinos, en conjunto, tienen tasas de paro relativamente bajas, pero trabajan en ocupaciones de cuello azul (manufacturación, agricultura) y en la economía informal (vendedores ambulantes, servicio doméstico). Así, los inmigrantes son un grupo constituido más por trabajadores pobres que por parados crónicos y trabajan en áreas dominadas por el pequeño comercio y el autoempleo.

Como ilustración se puede apuntar que en algunas áreas, la inmigración ha influido la economía local por medio del aumento de trabajos marginales para los recién llegados en el sector secundario y han contribuido a incrementar la competición en el mercado laboral con otros grupos urbanos minoritarios (ver Aponte, 1996). Así, aunque la inmigración está ligada a condiciones de pobreza, los estudios caracterizan a los inmigrantes como residentes que trabajan, a menudo ganando solo lo necesario para sobrevivir, y que se encuentran de forma habitual ligados al mercado laboral, aunque a menudo se trata de una vinculación a la economía sumergida (ver Moore y Pinderhughes, 1993).

Además, Wilson $(1987,1996)$ y Sampson (1987) también describen como estos vínculos a la economía constituyen un factor clave para el mantenimiento de las estructuras familiares, la estabilización de las instituciones comunitarias, y el descenso de los problemas sociales en los barrios urbanos. La consecuencia para el estudio de la delincuencia y de la violencia es que aunque la pobreza de los inmigrantes está tan extendida como la de las comunidades afroamericanas, su impacto en los niveles de violencia puede ser menor del esperado por los mayores vínculos que existen con el 
mercado laboral aunque sea un vinculo a través de trabajos mal pagados en los enclaves étnicos, así como por las tasas bajas de ruptura familiar (ver también Portes, 1996). Aunque esta interpretación es especulativa, constituye una razón plausible de porqué las tasas de delincuencia de los inmigrantes son más bajas de lo que cabría esperar. Evidentemente es necesario continuar estudiando este tema.

Mucha más investigación es necesaria sobre el vínculo de inmigración y delincuencia, particularmente sobre la última ola de inmigración, para avanzar nuestro conocimiento más allá de las conclusiones propuestas en este ensayo. Como otros autores, sugerimos que la investigación futura debería estar más abierta a considerar la posibilidad de que la inmigración puede tener un efecto positivo en las comunidades y en la reducción de la delincuencia. Estamos de acuerdo con Hagan y Palloni (1998, p. 382) cuando señalan que los investigadores deberían: "centrar su interés en encontrar formas por las que preservar, proteger y promover el capital social... que los inmigrantes traen con sus experiencias a los Estados Unidos, más que destacar cuestiones sobre su delincuencia y castigo".

El estudio académico de los inmigrantes que se limita a estudiar las pandillas y la delincuencia solamente puede servir para promover la impresión de que los inmigrantes son un grupo particularmente propenso a la comisión de delitos; una imagen que la investigación empírica de los últimos 100 años no respalda. En resumen, esta revisión sugiere que los residentes nativos podrían beneficiarse de un mejor entendimiento de cómo los grupos de inmigrantes a pesar de confrontar condiciones sociales adversas mantienen niveles de delincuencia comparativamente bajos ${ }^{\mathrm{iv}}$.

\footnotetext{
${ }^{\text {i }}$ El miedo de que muchos inmigrantes predispuestos a la criminalidad están entrando los Estados Unidos es una cuestión contemporánea, que se suma a otras razones para favorecer sentimientos en contra de la inmigración. En un libro que se convirtió en best-seller y en el que se prometía "sentido común sobre el desastre de la inmigración a América", un autor que colabora con Forbes y la National Review afirmaba: "La inmigración no es la única causa del delito. Puede que no sea siquiera la causa principal de la delincuencia. Pero es un factor" (Brimelow, 1996, 182). Caracterizada como una "historia de horror no ficticia de una nación que ciegamente se dirige hacia el suicidio nacional" (Jesse E. Todd, Jr., citado en la portada de Brimelow, 1996), este tipo de escritos alarmistas asume un vínculo fuerte entre inmigración y delincuencia sin aportar datos empíricos. De hecho, Brimelow (p. 182) alega que "no ha habido estudios académicos serios que examinen el impacto en la delincuencia" de la ola de inmigrantes que comenzó en 1965.

ii Aunque no es evidente en la Figura 1, la tasa de homicidios de latinos fluctuó desde un poco más del 16 por 100,000 habitantes en 1985 a un máximo de 18.6 en 1991, y descendió a un mínimo de 12.4 en 1996 (U.S. Department of Health and Human Services, 1998). El masivo aumento en inmigración legal no se tradujo en un aumento en las tasas de homicidios de latinos, que de hecho disminuyeron algo durante los 90. Las tasas de homicidios para los negros y los blancos también bajaron después de los años en los que la inmigración alcanzo su máximo. La tasa de homicidio para personas de color bajo de un máximo del 41.6 por 100.000 en 1991 al 29.9 en 1996, mientras que las tasas de blancos bajaron del 4.4 al 3.5. Así, las tasas de homicidio descendieron para todos los grupos tras la llegada de un gran número de inmigrantes.

iii Todas las tasas son por 100.000 personas por cada grupo específico tal y como fueron medidos por el censo de 1990.

${ }^{\text {iv }}$ Este proyecto no podría haberse realizado sin la generosa cooperación del anterior jefe de policía Donald Warshaw, el asistente del jefe John Brooks, el teniente Bobbie Meeks y el teniente John Campbell del Departamento de Policía de Miami. El anterior jefe de policia Jerry Sanders graciosamente abrio las puertas al Departamento de Policía de San Diego y los tenientes Glenn Breitenstein y Jim Collins amablemente facilitaron los archivos de homicidios. Un especial agradecimiento es debido a los detectives de ambos departamentos que trabajan en las unidades de investigación de homicidios que vieron su trabajo
} 
constantemente interrumpido por nuestra presencia. El Departamento de Policía de El Paso facilitó datos sobre homicidios a S. Fernando Rodríguez y también merece nuestras gracias. También nos gustaría agradecer a Robert Bursik y Gary LaFree por valiosos comentarios sobre versiones anteriores de este manuscrito. La financiación a Ramiro Martínez fue facilitada en parte por la National Science Foundation (SBR-9515235), una Beca Postdoctoral de la Ford Foundation, la Harry Frank Guggenheim Foundation y el National Consortium of Violence Research (NCOVR). NCOVR es financiado por la subvención SBR9513949 de la National Science Foundation. Las conclusiones presentadas en este articulo son las de los autores y no deberían interpretarse como el punto de vista de ninguna agencia oficial. Solamente nosotros, por supuesto, somos responsables de cualquier error en los datos.

\section{FIGURAS}

Tabla 1. Número total de inmigrantes y de inmigrantes latinos y tasa nacional de homicidios de latinos
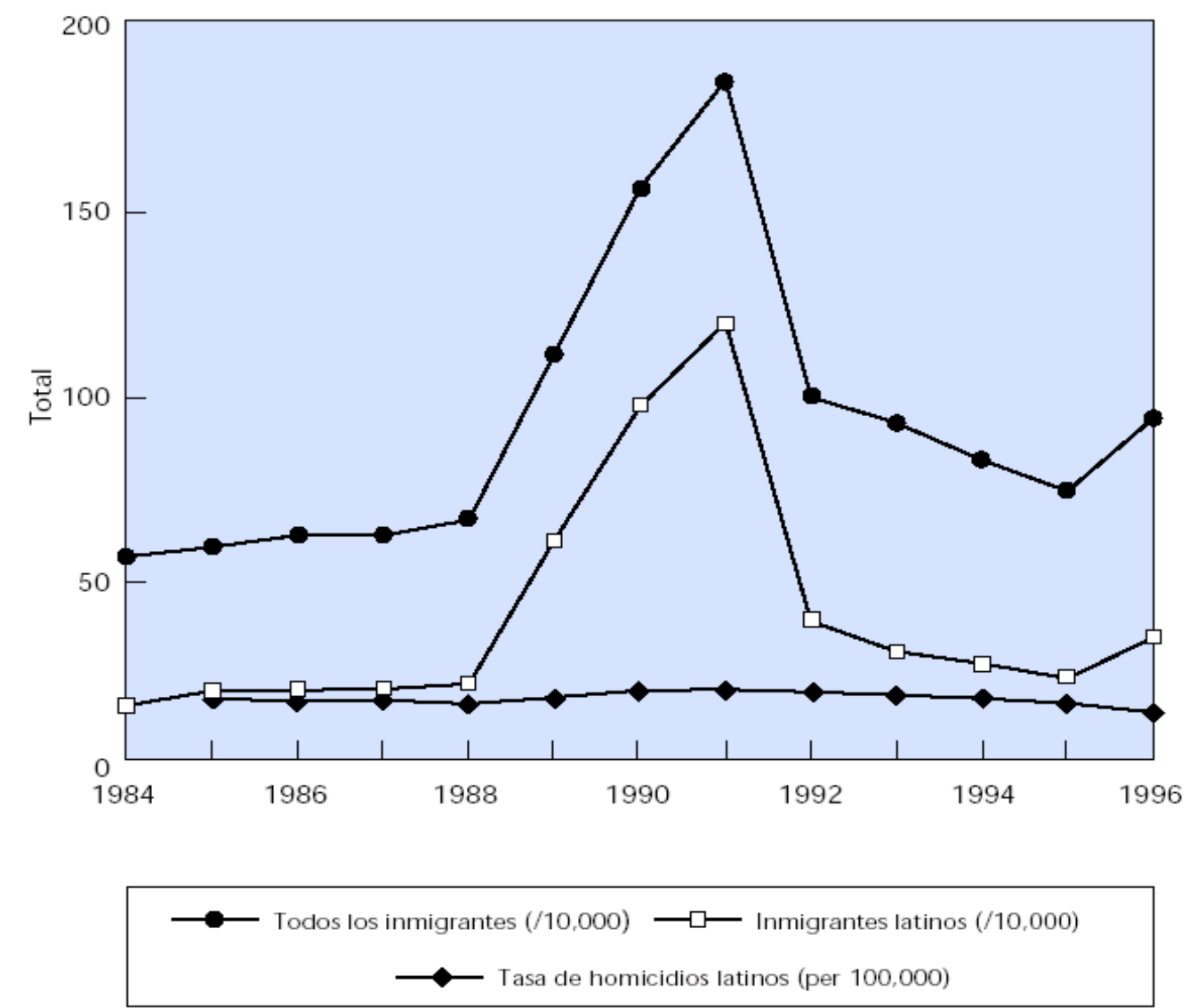

Fuentes: Las figuras sobre inmigración son publicadas por el U.S. Department of Justice, Immigration and Naturalization Services (1997, 1998); las tasas de homicidio están basadas en datos proporcionados por el U.S. Department of Health and Human Services, National Center for Health Statistics (1998). 
Figura 2. Porcentaje de una muestra de la población Americana que cree que varios grupos de inmigrantes han sido "una buena cosa para el país"

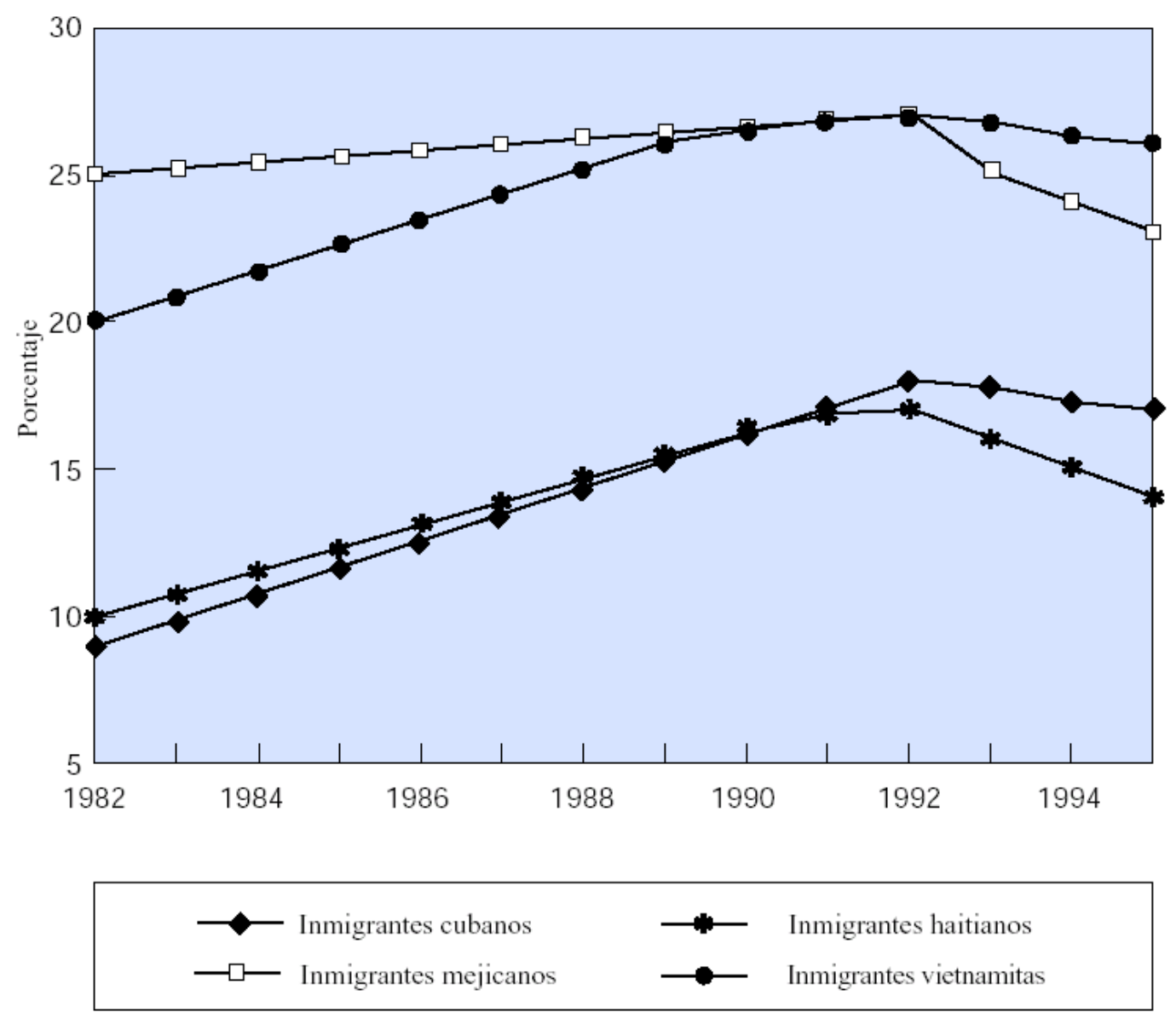

Fuentes: Informe Roper, 1995, pp. 113-114. 
Figura 3. Tasas totales de victimación por homicidio en tres ciudades

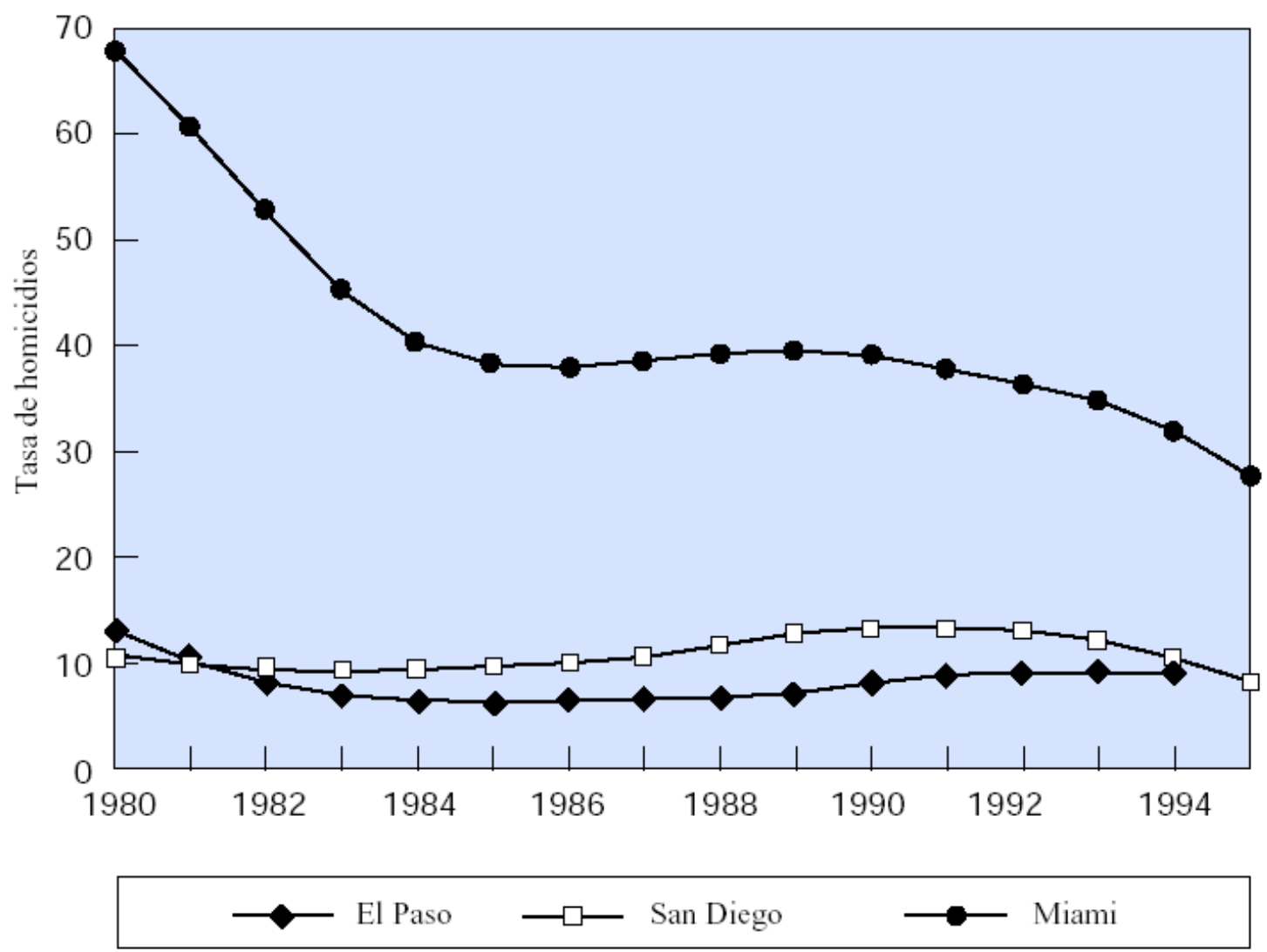

Fuentes: Datos sobre investigación de homicidios del Departamento de Policía de la Ciudad de El Paso 1980-1995; datos sobre investigación de homicidios del Departamento de Policía de Miami 1980-1995; datos sobre investigación de homicidios del Departamento de Policía de San Diego 1980-1995. Las estimaciones de la población están basados en datos del U.S. Bureau of the Census (1990). 
Figura 4. Tasa de victimación por homicidio de los marielitos en el contexto local y nacional

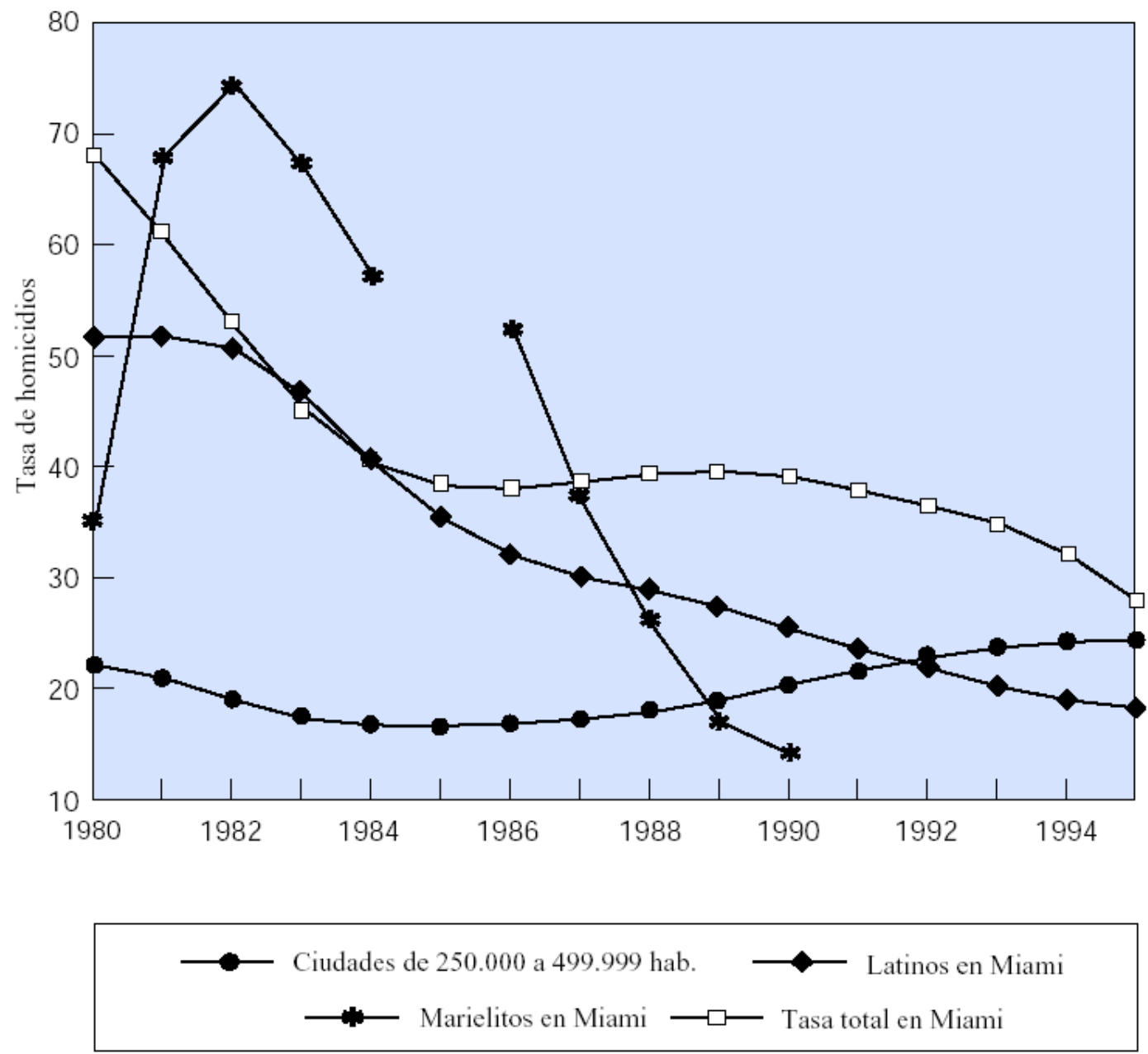

Fuentes: Datos sobre investigación de homicidios del Departamento de Policía de la ciudad de Miami 1980-1995. Las estimaciones de población están basadas en datos del U.S. Bureau of the Census (1990); las estimaciones de población de marielitos están basadas en los datos presentados por Portes, Clark y Manning (1985); las tasas de homicidios para todas las ciudades están basadas en datos del U. S. Department of Justice, Federal Bureau of Investigation (1980-1995). 
Figura 5. Tasa de victimación de latinos por homicidio en el contexto local y nacional
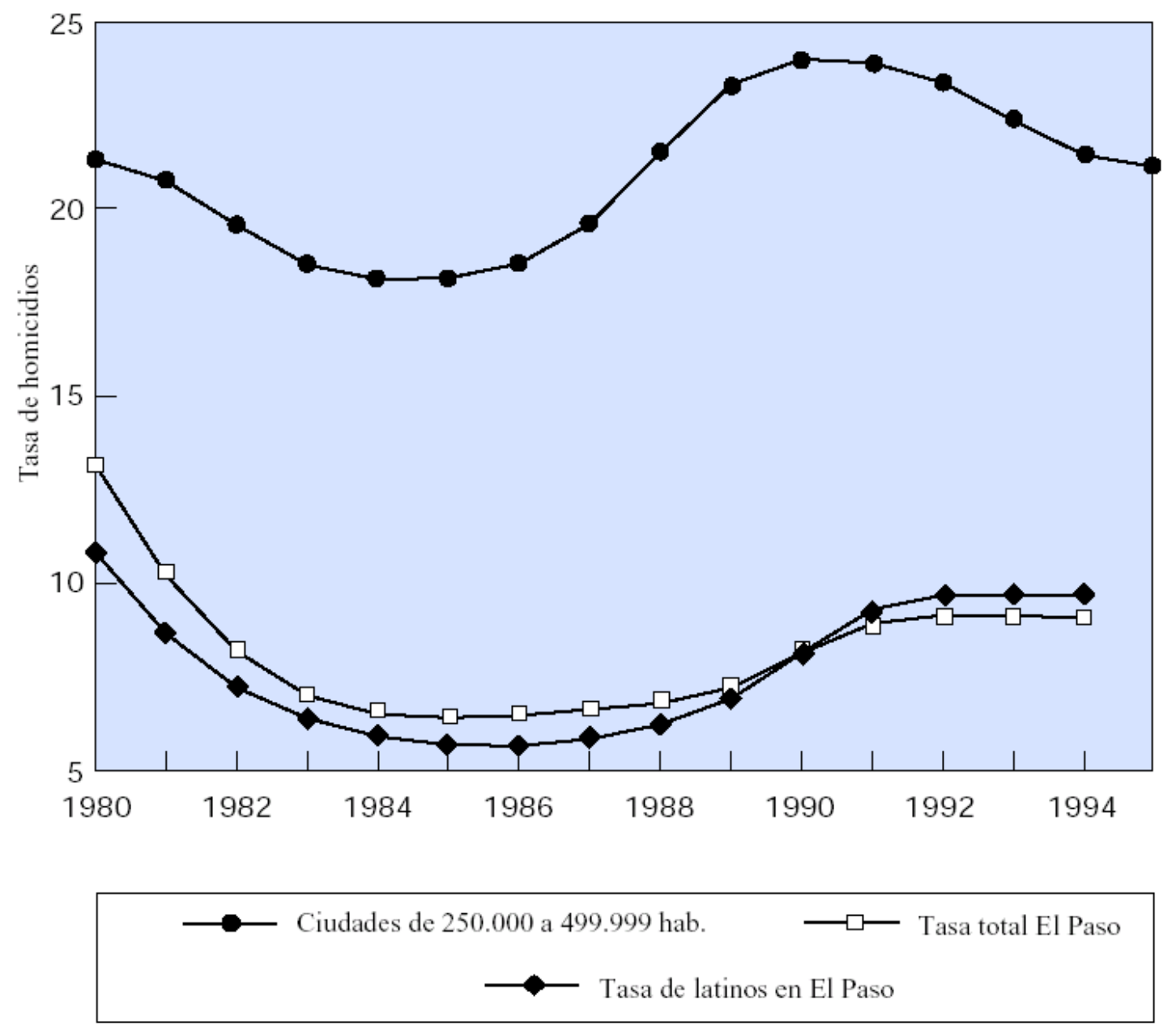

Fuentes: Datos sobre investigación de homicidios del Departamento de Policía de la ciudad de El Paso 980-1995. Las estimaciones de población están basadas en datos del U.S. Bureau of the Census (1990); las tasas de homicidios para todas las ciudades están basadas en datos del U. S. Department of Justice, Federal Bureau of Investigation (1980-1995). 
Figura 6. Tasa de victimación de latinos por homicidio en San Diego en el contexto local y nacional
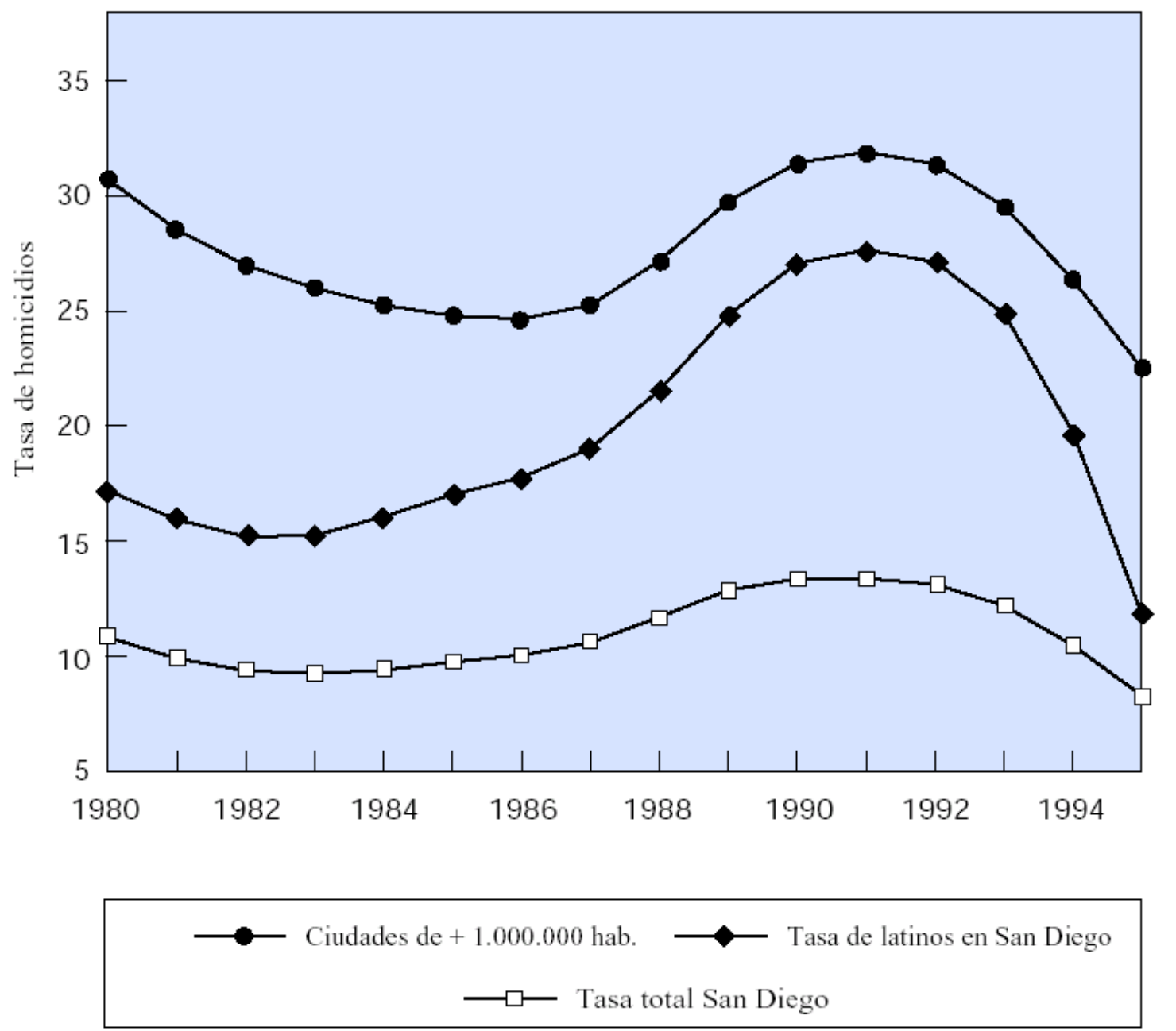

Fuentes: Datos sobre investigación de homicidios del Departamento de Policía de la ciudad de San Diego 1980-1995. Las estimaciones de población están basadas en datos del U.S. Bureau of the Census (1990); las tasas de homicidios para todas las ciudades están basadas en datos del U. S. Department of Justice, Federal Bureau of Investigation (1980-1995). 
Figura 7. Tasa de victimación de haitianos por homicidio en Miami en el contexto local y nacional

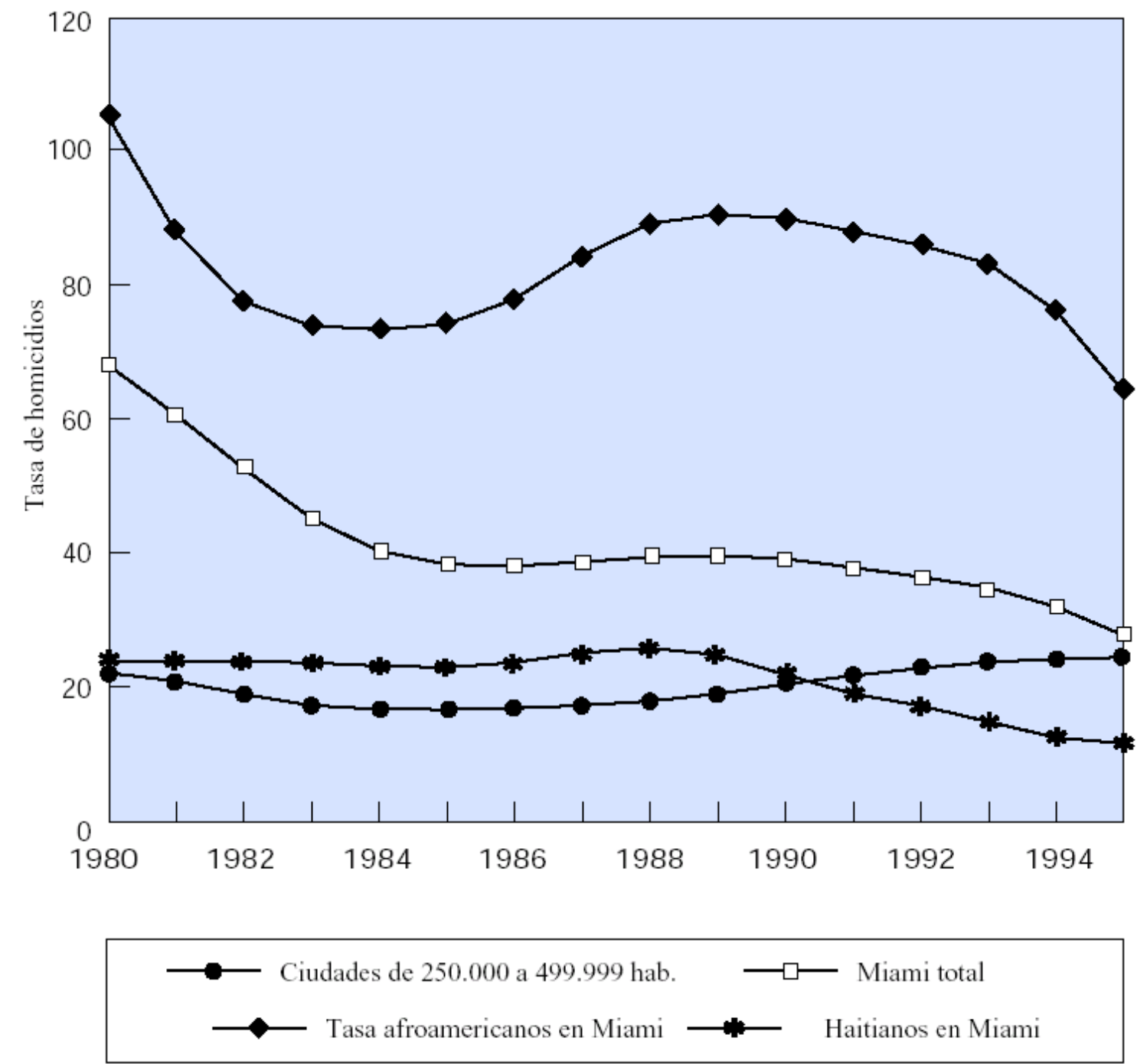

Fuentes: Datos sobre investigación de homicidios del Departamento de Policía de la ciudad de Miami 1980-1995. Las estimaciones de población están basadas en datos del U.S. Bureau of the Census (1990); las tasas de homicidios para todas las ciudades están basadas en datos del U. S. Department of Justice, Federal Bureau of Investigation (1980-1995). 
Figura 8. Tasa de victimación de asiáticos por homicidio en San Diego en el contexto local y nacional

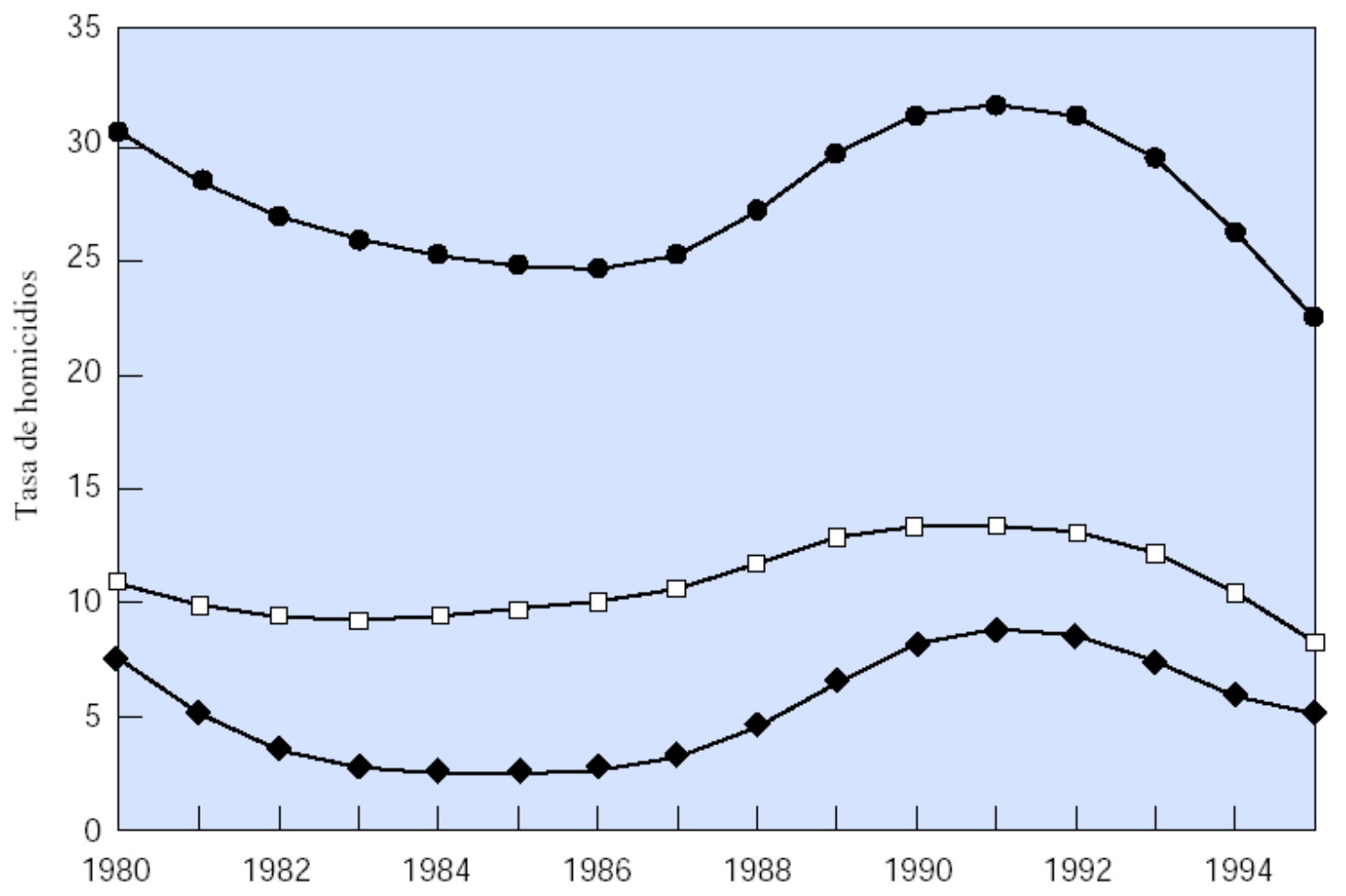

Ciudades de +1.000 .000 hab. $\square \square$ Tasa total San Diego $\longrightarrow$ Asiáticos en San Diego

Fuentes: Datos sobre investigación de homicidios del Departamento de Policía de la ciudad de San Diego 1 980-1995. Las estimaciones de población están basadas en datos del U.S. Bureau of the Census (1990); las tasas de homicidios para todas las ciudades están basadas en datos del U. S. Department of Justice, Federal Bureau of Investigation (1980-1995).

\section{BIBLIOGRAFÍA}

Abbott, Edith. 1931. The problem of crime and the foreign born. In Report on crime and the foreign born. National Commission on Law Observance and Enforcement Report no. 10. Washington, D.C.: U.S. Government Printing Office. Abbott, G. 1915. Immigration and crime. Journal of Criminal Law and Criminology6:522-532.

Alaniz, Maria Luisa, Randi S. Cartmill, y Robert Nash Parker. 1998. Immigrants and violence: The importance of neighborhood context. Hispanic Journal of Behavioral Sciences 20 (May): 155-174.

Aguirre, B.E., Rogelio Saenz, y Brian Sinclair James. 1997. Marielitos ten years later: The Scarface legacy. Social Science Quarterly 78 (June): 487-507.

Anderson, Elijah. 1990. Streetwise: Race, class, and change in an urban community. Chicago: University of Chicago Press.

Aponte, Robert. 1996. Urban unemployment and the mismatch dilemma: Accounting for the immigration exception. Social Problems 43 (August): 268-283.

Baker, Susan Gonzalez, Frank D. Bean, Augustin Escobar Latapi, y Sidney Weintraub. 1998. U.S. immigration policies and trends: The growing importance of migration from Mexico. En Crossings: Mexican immigration in interdisciplinary perspectives, editado por M.M. Suarez-Orozco. Cambridge: Harvard University Press.

Bankston, Carl L., III. 1998. Youth gangs and the new second generation: A review essay. Aggression and Violent Behavior 3 (1): 35-45.

Beck, Roy. 1996. The case against immigration. New York: W.W. Norton. 
Bowler, Alida C. 1931. Recent statistics on crime and the foreign born. En Report on crime and the foreign born. National Commission on Law Observance and Enforcement Report no. 10. Washington, D.C.: U.S. Government Printing Office.

Bradshaw, Benjamin, David R. Johnson, Derral Cheatwood, y Stephen Blanchard. 1998. A historical geographical study of lethal violence in San Antonio. Social Science Quarterly 79 (December): 863-878.

Brimelow, Peter J. 1996. Alien nation. New York: HarperPerennial.

Bursik, Robert J. 1988. Social disorganization and theories of crime and delinquency: Problems and prospects. Criminology 26 (November): 519-551.

Chin, Ko-lin. 1990. Chinese subculture and criminality: Non-traditional crime groups in America. Westport, Connecticut: Greenwood Press.

Cloward, Richard, y Lloyd Ohlin. 1960. Delinquency and opportunity: A theory of delinquent gangs. New York: Free Press.

Du Phuoc Long, Patrick. 1996. The dream shattered: Vietnamese gangs in America. Boston: Northeastern University

Press.

Epstein, Gail, y Ronnie Greene. 1993. Dade's crime rate is highest in U.S., Florida is 1st among States. Miami Herald, 3 October.

Espenshade, Thomas J., y Maryanne Belanger. 1998. Immigration and public opinion. en Crossings: Mexican immigration in interdisciplinary perspectives, editado por M.M. Suarez-Orozco. Cambridge: Harvard University Press. Ferracuti, Franco. 1968. European migration and crime. En Crime and culture: Essays in honor of Thorsten Sellin, editado por M.E. Wolfgang. New York: John Wiley \& Sons.

Gans, Herbert J. 1992. Second generation decline: Scenarios for the economic and ethnic futures of the post-1965 American immigrants. Ethnic and Racial Studies 15:173-192.

Glueck, Sheldon, y Eleanor Glueck.1930. Five hundred criminal careers. New York: Alfred A. Knopf.

Gurr, Ted Robert. 1989. The history of violent crime in America. En Violence in America, editado por T.R. Gurr. Vol. 1. Newbury Park, California: Sage Publications.

Hagan, John, y Alberto Palloni. 1998. Immigration and crime in the United States. En The immigration debate, editado por J.P. Smith y B. Edmonston. Washington, D.C.: National Academy Press.

Handlin, Oscar. 1959. The newcomers: Negroes and Puerto Ricans in a changing metropolis. Cambridge: Harvard University Press.

Hawkins, Darnell F. 1999. African Americans and homicide. En Issues in the study and prevention of homicide, editado por M.D. Smith y M. Zahn. Thousand Oaks, California: Sage Publications.

Hayner, Norman S. 1933. Delinquency areas in the Puget Sound region. American Journal of Sociology 39

(November): 314-328.

Jonassen, Christen T. 1949. A re-evaluation and critique of the logic and some methods of Shaw and McKay. American Sociological Review 14 (October): 608-614.

Kobrin, Solomon. 1959. The Chicago Area Project: A 25 year assessment. Annals of the American Academy of Political and Social Science 322 (March): 19-29.

Lambert, John R. 1970. Crime, police, and race relations: A study in Birmingham. London: Oxford University Press. Lane, Roger. 1997. Murder in America: A history. Columbus: Ohio State University Press.

Laughlin, Harry H. 1939. Immigration and conquest. New York: Special Committee on Immigration and Naturalization of the Chamber of Commerce of the State of New York.

Lee, Matthew T., Ramiro Martinez, Jr., y S. Fernando Rodriguez. 2000. Contrasting Latinos in homicide research: The victim and offender relationship in El Paso and Miami. Social Science Quarterly 81 (1): 375-388.

Lee, Yoon Ho. 1998. Acculturation and delinquent behavior: The case of Korean American youths. International Journal of Comparative and Applied Criminal Justice 22 (Fall): 273-292.

Lewis, Oscar. 1965. La vida: A Puerto Rican family in the culture of poverty. New York: Random House.

Lind, Andrew W. 1930a. The ghetto and the slum. Social Forces 9 (December): 206-215. 1930b. Some ecological patterns of community disorganization in Honolulu. American Journal of Sociology 36 (September): 206-220.

Marshall, Ineke Haen. 1997. Minorities, migrants, and crime: Diversity and similarity across Europe and the United States. Thousand Oaks, California: Sage Publications.

Martinez, Ramiro, Jr. 1997a. Homicide among the 1980 Mariel refugees in Miami: Victims and offenders. Hispanic Journal of Behavioral Sciences 19 (May): 107-122.

. 1997b. Homicide among Miami's ethnic groups: Anglos, blacks, and Latinos in the 1990s. Homicide Studies 1 (May): 17-34.

1996. Latinos and lethal violence: The impact of poverty and inequality. Social Problems 43 (May): 131-146.

Martinez, Ramiro, Jr., y Matthew T. Lee. Próximamente. Comparing the context of immigrant homicides in Miami: Haitians, Jamaicans, and Mariels. International Migration Review.

- 1999. Extending ethnicity in homicide research: The case of Latinos. En Homicide: A sourcebook of social research, editado por M.D. Smith y M. Zahn. Newbury Park, California: Sage Publications.

Revista de Española de Investigación Criminólogica

REIC NI-01-04 http://www.criminologia.net/revista 
1998. Immigration and the ethnic distribution of homicide in Miami, 1985-1995. Homicide Studies 2 (August): 291-304.

McCord, Joan. 1995. Ethnicity, acculturation, and opportunities: A study of two generations. In Ethnicity, race, and crime, editado por D.F. Hawkins. Albany: State University of New York Press.

Merton, Robert K. 1938. Social structure and anomie. American Sociological Review 3 (October): 672-682.

Monkkonen, Eric H. 1989. Diverging homicide rates: England and the United States, 1850-1875. En Violence in America, editado por T.R. Gurr. Vol. 1. Newbury Park, California: Sage Publications.

Moore, Joan, y Raquel Pinderhughes. 1993. In the barrios: Latinos and the underclass debate. New York: Russell Sage Foundation.

Ousey, Graham C. 1999. Homicide, structural factors, and the racial invariance assumption. Criminology 37 (May): 405-426.

Padilla, Amado M. 1980. Acculturation: Theory, models, and some new findings. Boulder, Colorado: Westview Press. Portes, Alejandro. 1996. The new second generation. New York: Russell Sage Foundation.

Portes, Alejandro, Juan M. Clark, y R.D. Manning. 1985. After Mariel: A survey of the resettlement experiences of 1980 Cuban refugees in Miami. Cuban Studies 15:37-59.

Portes, Alejandro, y Alex Stepick. 1993. City on the edge: The transformation of Miami. Berkeley: University of California Press.

Roper Reports. 1995. Roper Report 95-4. New York: Roper Starch Worldwide, June.

Rosenwaike, Ira, y Katherine Hempstead. 1990. Mortality among three Puerto Rican populations: Residents of Puerto Rico and migrants in New York City and in the balance of the United States, 1979-81. International Migration Review 24 (Winter): 684-702.

Ross, Harold. 1937. Crime and the native born sons of European immigrants. Journal of Criminal Law and Criminology 28 (July-August): 202-209.

Sampson, Robert J. 1987. Urban black violence: The effect of male joblessness and family disruption. American Journal of Sociology 93 (September): 348-382.

Sampson, Robert J., y Janet L. Lauritsen. 1997. Racial and ethnic disparities in crime and criminal justice in the United States. En Ethnicity, crime, and immigration. Vol. 21 of Crime and justice: A review of research, editado por M.

Tonry. Chicago: University of Chicago Press.

Sampson, Robert J., y William Julius Wilson. 1995. Toward a theory of race, crime, and urban inequality. En Crime and inequality, editado por J. Hagan y R. Peterson. Stanford, California: Stanford University Press.

Sanchez-Jankowski, Martin. 1991. Islands in the street: Gangs and American urban society. Berkeley: University of California Press.

Scalia, John. 1996. Noncitizens in the Federal criminal justice system, 1984-1994. Special Report, NCJ 160934.

Washington, D.C.: U.S. Department of Justice, Bureau of Justice Statistics.

Schneider, Hans Joachim. 1995. Foreigners as perpetrators and as victims in Germany. EuroCriminology 8-9:95-108.

Sellin, Thorsten. 1938. Culture conflict and crime. New York: Social Science Research Council.

Shaw, Clifford R., y Henry D. McKay. [1942] 1969. Juvenile delinquency and urban areas. Chicago: University of Chicago Press.

- 1931. Social factors in juvenile delinquency. In Report on the causes of crime. National Commission on Law Observance and Enforcement Report no. 13. Washington, D.C.: U.S. Government Printing Office.

Short, James F. 1997. Poverty, ethnicity, and violent crime. Boulder, Colorado: Westview Press.

Simon, Rita J. 1993. Old minorities, new immigrants: Aspirations, hopes, and fears. Annals of the American Academy of Political and Social Science 30 (November): 61-73.

- 1987. Immigration and American attitudes. Public Opinion 10 (July-August): 47-50.

- 1985. Public opinion and the immigrant: Print media coverage, 1880-1980. Lexington, Massachusetts:

Lexington Books.

Stepick, Alex. 1998. Pride against prejudice: Haitians in the United States. Boston: Allyn and Bacon.

Suarez-Orozco, Marcelo M. 1998. Introduction to Crossings: Mexican immigration in interdisciplinary perspectives, edited by M.M. Suarez-Orozco. Cambridge: Harvard University Press.

Sutherland, Edwin H. 1947. Principles of criminology. 4th ed. Chicago: J.B. Lippincott. . 1934. Principles of criminology. Chicago: J.B. Lippincott.

Sutherland, Edwin H., y Donald R. Cressey. 1960. Principles of criminology. 6th ed. Chicago: J.B. Lippincott.

Taft, Donald R. 1936. Nationality and crime. American Sociological Review 1 (October): 724-736.

Taylor, Paul S. 1931. Crime and the foreign born: The problem of the Mexican. In Report on crime and the foreign born. National Commission on Law Observance and Enforcement Report no. 10. Washington, D.C.: U.S. Government Printing Office.

Thomas,William I., y Florian Znaniecki. [1920] 1984. The Polish peasant in Europe and America: Edited and abridged. Chicago: University of Illinois Press.

-1920. The Polish peasant in Europe and America: Volume IV, disorganization and reorganization in Poland. Boston: Gorham Press.

Revista de Española de Investigación Criminólogica

REIC NI-01-04 http://www.criminologia.net/revista 
Tonry, Michael. 1997. Ethnicity, crime, and immigration. En Ethnicity, crime, and immigration. Vol. 21 of Crime and justice: A review of research, editado por M. Tonry. Chicago: University of Chicago Press.

U.S. Bureau of the Census. 1990. 1990 census of population and housing. Summary tape file 3A. Descargado el 30 de marzo del 2000: http://venus.census.gov/cdrom/lookup.

U.S. Commission on Immigration Reform. 1994. Restoring credibility. Washington, D.C.: U.S. Commission on Immigration Reform.

U.S. Department of Health and Human Services, National Center for Health Statistics. 1998. Health, United States, 1998: With socioeconomic status and health chartbook. Hyattsville, Maryland.

U.S. Department of Justice, Federal Bureau of Investigation. 1997. Crime in the United States-1996. Descargado el 12 de enero 2000: http://www.fbi.gov/ucr/Cius_97/96CRIME/96crime2.pdf.

1980-95. Crime in the United States. Uniform Crime Reports. Washington, D.C.

U.S. Department of Justice, Immigration and Naturalization Service. 1997. Statistical yearbook of the Immigration and Naturalization Service, 1996. Washington, D.C.

1987. Statistical yearbook of the Immigration and Naturalization Service, 1986. Washington, D.C.

Vidal, Gore. 1986. The empire lovers strike back. Nation, 22 March, 350. Citado en Karl Zinsmeister, Asians:

Prejudice from top and bottom, Public Opinion 10 (July-August 1987): 10.

Vigil, James D., y J.M. Long. 1990. Emic and etic perspectives of gang culture: The Chicano case. En Gangs in

America, editado por C.R. Huff. Newbury Park: Sage Publications.

Von Hentig, Hans. 1945. The first generation and a half: Notes on the delinquency of the native white of mixed parentage. American Sociological Review 10 (December): 792-798.

Warnshuis, Paul Livingstone. 1931. Crime and criminal justice among the Mexicans of Illinois. In Report on crime and the foreign born. National Commission on Law Observance and Enforcement Report no. 10. Washington, D.C.: U.S.

Government Printing Office.

Whyte, William Foote. 1943. Social organization in the slums. American Sociological Review 8 (February): 34-39.

Wilbanks, William. 1984. Murder in Miami: An analysis of homicide patterns and trends in Dade County (Miami)

Florida, 1917-1983. Lanham, Maryland: University Press of America.

Wilson, William J. 1996. When work disappears: The world of the new urban poor. New York: Alfred A. Knopf.

. 1987. The truly disadvantaged. Chicago: University of Chicago Press.

Wolfgang, Marvin E. 1958. Patterns in criminal homicide. Philadelphia: University of Pennsylvania Press.

Wolfgang, Marvin, y Franco Ferracuti. 1967. The subculture of violence: Towards an integrated theory in criminology.

London: Tavistock.

Yeager, Matthew G. 1997. Immigrants and criminality: A review. Criminal Justice Abstracts 29 (March): $143-171$.

Young, Pauline V. 1936. Social problems in the education of the immigrant child. American Sociological Review 1

(June): 419-429.

Zinsmeister, Karl. 1987. Asians: Prejudice from top and bottom. Public Opinion 10 (July-August): 8-10, 59.

\section{LOS AUTORES}

Ramiro Martinez, Jr. es profesor asociado de justicia criminal y salud pública en la Universidad Internacional de Florida en Miami, Florida. Martínez es miembro del National Consortium on Violence Research, el National Hispanic Science Network on Drug Abuse, y recientemente recibió el Premio a las Contribuciones Distinguidas de la Sección Latina de la Asociación Americana de Sociología como reconocimiento de su trabajo investigador a lo largo de su carrera professional. Ha publicado numerosas contribuciones en el area de etnicidad, homicidios y violencia y es el autor de Latino Homicide: Immigration, Violence and Community (Routledge Press, 2002). También es el investigador principal del Estudio sobre Violencia Latina financiado por el Latino Minority Drug Abuse Research Center (NIDA, R24-1R24PA014260).

Matthew Lee es profesor ayudante de sociología en la Universidad de Akron, Ohio. Sus áreas generales de interés son el estudio de la delincuencia, inmigración, y violencia.

Revista de Española de Investigación Criminólogica 